\title{
Vertical sorting and the morphodynamics of bed form-dominated rivers: A sorting evolution model
}

\author{
Astrid Blom, ${ }^{1,2}$ Jan S. Ribberink, ${ }^{1}$ and Gary Parker ${ }^{3}$ \\ Received 29 June 2006; revised 26 July 2007; accepted 26 October 2007; published 14 March 2008.
}

[1] Existing sediment continuity models for nonuniform sediment suffer from a number of shortcomings, as they fail to describe vertical sorting fluxes other than through net aggradation or degradation of the bed and are based on a discrete representation of the bed material interacting with the flow. We present a new type of sediment continuity model that is based on a stochastic description of the bed surface rather than discrete bed layers. The model is aimed at conditions dominated by bed load transport wherein the river bed is fully covered by river dunes. Application of the model should be limited to spatial scales covering a significant number of bed forms. The resulting model, i.e., the sorting evolution model, is suitable for unsteady conditions, as it takes into account the time evolution of, for instance, vertical sorting in modeling net aggradation or degradation of the river bed. The present paper lists the various submodels of a morphodynamic model system to which the sorting evolution model is applied. We compare the results of the morphodynamic model system to measured data from two flume experiments. The new model shows reasonable results for the predicted time evolution of the vertical sorting profile, as well as the time evolution of the grain size distribution of the bed load transport. Yet the model does not properly include sorting mechanisms associated with partial transport and the winnowing of fines from the trough surface and subsurface. The model serves as a basis for a future simplification of the model into a new stochastics-based bed layer type sediment continuity model in which vertical sediment fluxes are included in a parameterized way.

Citation: Blom, A., J. S. Ribberink, and G. Parker (2008), Vertical sorting and the morphodynamics of bed form-dominated rivers: A sorting evolution model, J. Geophys. Res., 113, F01019, doi:10.1029/2006JF000618.

\section{Introduction}

[2] Morphodynamic model systems are used to gain insight into, for instance, the effects of human interventions on a river system. A morphodynamic model system is here defined as a system that couples modules for calculating flow, sediment transport, and net aggradation or degradation of the river bed. In case sediment sorting processes play a role, the model system needs to include a sediment continuity model for nonuniform sediment, which takes into account the effects of grain size-selective sediment transport in modeling large-scale aggradation or degradation of the (river) bed. Hirano [1970, 1971, 1972] was the first to develop such a sediment continuity model for nonuniform sediment, and proposed to represent the active part of the bed as a distinct homogeneous surface layer. Yet, this

\footnotetext{
${ }^{1}$ Water Engineering and Management, Civil Engineering, University of Twente, Enschede, Netherlands.

${ }^{2}$ Now at Environmental Fluid Mechanics Section, Civil Engineering and Geosciences, Delft University of Technology, Delft, Netherlands.

${ }^{3}$ Department of Civil and Environmental Engineering and Department of Geology, University of Illinois at Urbana-Champaign, Urbana, Illinois, USA.

Copyright 2008 by the American Geophysical Union. 0148-0227/08/2006JF000618\$09.00
}

commonly used Hirano active layer model and its variants suffer from three main shortcomings. First, in most of the Hirano-type bed layer models vertical sediment fluxes occur through net aggradation or degradation only, whereas flume experiments have shown that this is not true [Ribberink, 1987; Blom et al., 2003]. Ribberink [1987] and Di Silvio [1992] introduce an additional layer below the active layer in order to account for vertical sediment exchange due to occasionally deep bed form troughs. Second, in certain situations the set of equations of sediment continuity models with discrete bed layers becomes elliptic in parts of the space-time domain [Ribberink, 1987]. Solving the set of equations then requires future time boundaries, which is physically unrealistic. Finally, from a physical point of view it is not straightforward to distinguish between the range of bed elevations interacting with the flow regularly (i.e., the active layer), the range interacting with the flow only occasionally (i.e., the exchange layer in the Ribberink [1987] two-layer model), and the range not interacting with the flow, at all (i.e., the substrate). In morphodynamic river models the bed layers' thicknesses are therefore usually simply used as calibration parameters.

[3] In reality, the active part of the bed is represented by a probability density function (PDF) of bed surface elevations rather than by discrete bed layers, and in most cases is not homogeneous. Parker et al. [2000] have introduced a 


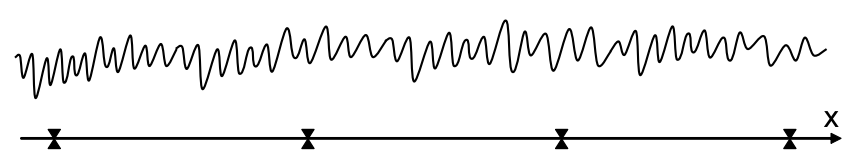

Figure 1. Longitudinal profile of bed elevations, together with grid points in $\mathrm{x}$ direction of the morphodynamic model system to which the sorting evolution model is applied.

framework for sediment continuity without discrete bed layers, which allows us to take into account that relatively deep bed elevations interact with the flow and are subject to entrainment and deposition less frequently than higher ones. Blom and Parker [2004] derive formulations for the grain size-specific and bed elevation-specific entrainment and deposition fluxes as required for the framework, for situations dominated by bed load transport wherein the river bed is fully covered by river dunes. They apply the Einstein [1950] formulation for step length to the stoss face of a bed form, which relates deposition of particles over the stoss face to entrainment. A lee sorting function describes the grain size selective deposition of particles over the lee face. The variability in bed form dimensions is taken into consideration by accounting for the PDF of bed form trough elevations. All bed forms are assumed to have a triangular shape, and the geometric properties of an individual bed form (e.g., bed form height and bed form length) are assumed to be related to the trough elevation according to simple relations. As such, the likelihood of occurrence of a specific bed form is characterized by the PDF of relative trough elevations. Application of the model should be limited to spatial scales covering a significant number of bed forms (Figure 1).

[4] Whereas Blom et al. [2006] have reduced the Blom and Parker [2004] model to steady or equilibrium conditions, i.e., conditions in which all variables vary around mean values, in the present paper we consider unsteady conditions and reduce the model to a sorting evolution model. The purpose of this new sediment continuity model is to account for the effects of the time evolution of both the grain size-selective transport and the vertical sorting profile in modeling large-scale morphodynamic changes, i.e., net aggradation or degradation, of the river bed. Application of the sorting evolution model in a morphodynamic model system requires a number of submodels. In section 2 we explain what type of submodels are required and how they are integrated in the morphodynamic model system. Among these submodels are models for three types of vertical sediment fluxes, which are described in section 3. In section 4 we discuss the various timescales involved in the application of the model.

[5] Besides its derivation, the present paper presents the results of the application of the new sediment continuity model to two flume experiments (section 5). The experiments are characterized by bed load transport wherein the bed is fully covered by bed forms. Furthermore, the experiments are governed by uniform conditions and sediment recirculation, and, as such, net aggradation or degradation did not occur. The morphodynamic model system computes the time evolution of both the vertical sorting profile and the composition of the bed load transport. For the input param- eters (the time evolution of the PDF of relative trough elevations, the total rate of bed load transport), we use measured data rather than predictive submodels, so as to minimize the uncertainties in the model results. We have compared the results of the morphodynamic model system to measured data.

\section{Morphodynamic Model System}

[6] Figure 2 shows an overview of the various submodels in a morphodynamic model system to which the sorting evolution model is applied. Submodels are required for describing (1) the sorting evolution model, which involves formulations for three types of vertical sediment fluxes (I, II, and III); (2) the PDF of relative trough elevations; (3) the mean composition of the bed surface; (4) the hydraulic roughness; (5) the flow; (6) the total bed load transport rate; and (7) suspended load transport. These submodels are described in sections $2.1-2.7$.

\subsection{Sorting Evolution Model}

[7] The sorting evolution model is based on the Parker et al. [2000] framework for sediment continuity. In this framework the active part of the bed is described by a PDF of bed surface elevations rather than a discrete and

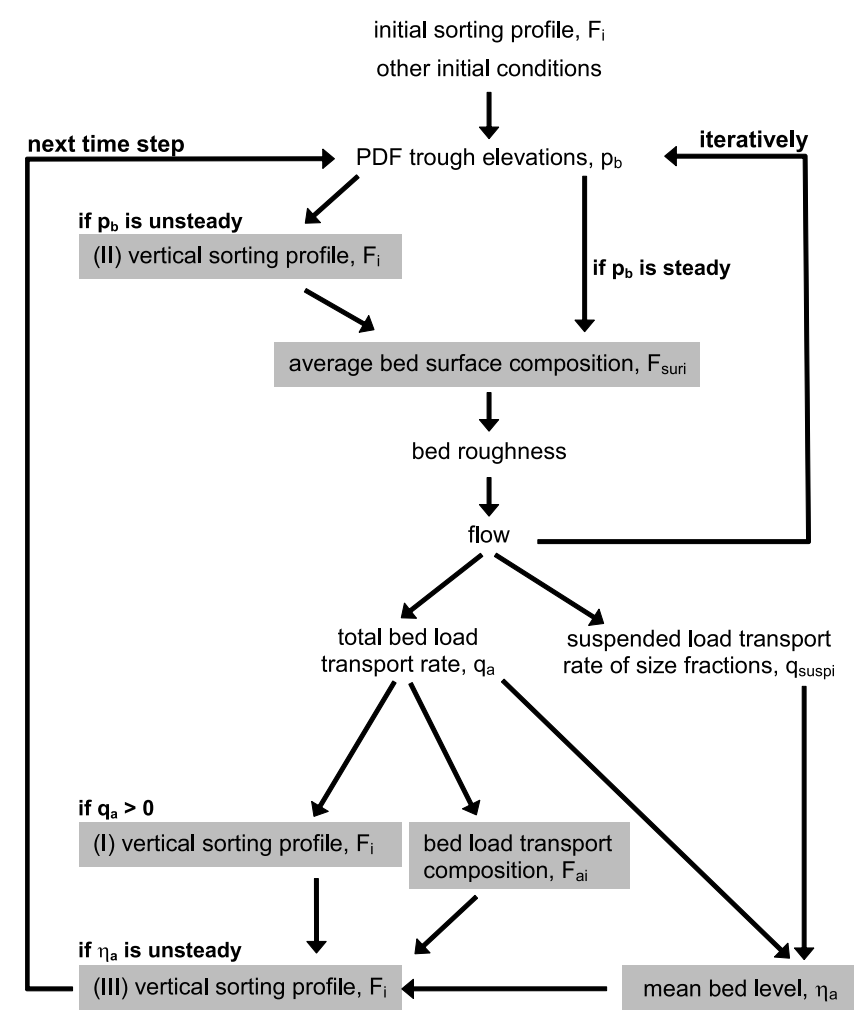

Figure 2. Scheme of a morphodynamic model system for nonuniform sediment to which the sorting evolution model is applied. Gray boxes represent submodels that are part of the sorting evolution model. Evolution of the vertical sorting profile occurs through vertical sediment fluxes accompanying dune migration (type I), a change in time of the PDF of relative trough elevations (type II), and net aggradation or degradation (type III). 


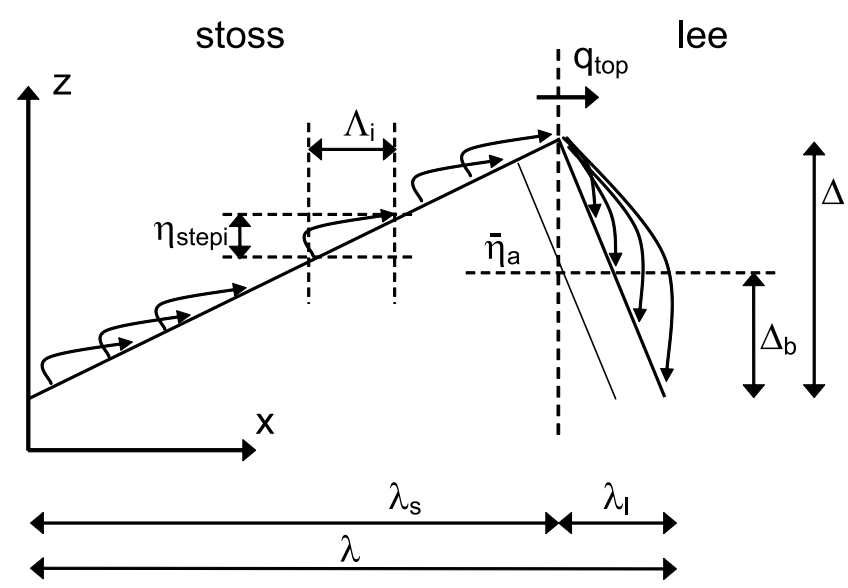

Figure 3. Bed form parameters and division of bed form in stoss and lee sides with accompanying entrainment and deposition fluxes.

homogeneous active layer of sediment. Sediment conservation of size fraction $i$ at elevation $z$ is now given by

$$
\frac{\partial \bar{C}_{i}}{\partial t}=c_{b} \bar{P}_{s} \frac{\partial \bar{F}_{i}}{\partial t}+c_{b} \bar{F}_{i} \frac{\partial \bar{P}_{s}}{\partial t}=\bar{D}_{e i}-\bar{E}_{e i}
$$

where $\bar{C}_{i}$ denotes the concentration of size fraction $i$ at elevation $z\left(\bar{C}_{i}=c_{b} \bar{P}_{s} \bar{F}_{i}\right), \bar{F}_{i}$ denotes the volume fraction content of size fraction $i$ in the bed at elevation $z$, and $\bar{P}_{s}$ denotes the probability distribution of bed surface elevations, indicating the probability that the bed surface elevation is higher than $z . \bar{D}_{e i}$ denotes the deposition density of size fraction $i$ defined such that $\bar{D}_{e i} d x d z$ is the volume of sediment of size fraction $i$ that is deposited in a bed element with sides $d x$ and $d z$ at elevation $z$ per unit width and time, $\bar{E}_{e i}$ denotes the entrainment density of size fraction $i$ defined likewise, and $c_{b}$ the sediment concentration within the bed $\left(c_{b}=1-\lambda_{b}\right.$, where $\lambda_{b}$ denotes the porosity). The overbar indicates that a parameter is averaged over some horizontal distance, e.g., a large number of bed forms, which is indicated by the term overall. The coordinate $x$ denotes the horizontal coordinate on a spatial scale of a large series of bed forms (Figure 1), $z$ denotes the vertical coordinate, and $t$ denotes the time coordinate.

[8] Applying a coordinate transformation $(\tilde{x}=x, \tilde{t}=t$, and $\tilde{z}=z-\bar{\eta}_{a}$ wherein the tilde denotes a parameter is relative to the bed surface elevation averaged over a series of bed forms (i.e., the mean bed level), $\bar{\eta}_{a}$, and $\tilde{z}$ denotes the vertical coordinate relative to the mean bed level, $\bar{\eta}_{a}$ ), and the chain rule yields

$$
\frac{\partial \bar{P}_{s}}{\partial t}=\frac{\partial \tilde{P}_{s}}{\partial t}+\bar{p}_{e} \frac{\partial \bar{\eta}_{a}}{\partial t}
$$

where $\tilde{P}_{s}$ denotes the probability distribution of bed surface elevations for a series of bed forms relative to the mean bed level, $\bar{\eta}_{a}$. The PDF of bed surface elevations for a series of bed forms, $\bar{p}_{e}$, expresses the probability density function of bed surface elevations for a series of bed forms, indicating the probability density that the bed surface elevation equals $z$ or the likelihood of elevation $z$ being exposed to the flow $\left(\bar{p}_{e}=-\partial \bar{P}_{s} / \partial z=-\partial \tilde{P}_{s} / \partial \tilde{z}\right)$. With equation (2), equation (1) becomes

$$
c_{b} \bar{P}_{s} \frac{\partial \bar{F}_{i}}{\partial t}+c_{b} \bar{F}_{i} \frac{\partial \tilde{P}_{s}}{\partial t}+c_{b} \bar{F}_{i} \bar{p}_{e} \frac{\partial \bar{\eta}_{a}}{\partial t}=\bar{D}_{e i}-\bar{E}_{e i}
$$

Adding up equation (3) over all grain sizes yields

$$
c_{b} \frac{\partial \tilde{P}_{s}}{\partial t}+c_{b} \bar{p}_{e} \frac{\partial \bar{\eta}_{a}}{\partial t}=\bar{D}_{e}-\bar{E}_{e}
$$

where $\bar{D}_{e}$ denotes the deposition density defined such that $\bar{D}_{e} d x d z$ is the volume of sediment of all size fractions deposited in a bed element with sides $d x$ and $d z$ at elevation $z$ per unit width and time $\left(\bar{D}_{e}=\sum_{i}^{N} \bar{D}_{e i}\right.$ where $N$ denotes the total number of size fractions) and $\bar{E}_{e}$ denotes the entrainment density defined likewise.

[9] Integration of equation (4) over all bed elevations yields

$$
c_{b} \frac{\partial \bar{\eta}_{a}}{\partial t}=\bar{D}-\bar{E}\left(=-\frac{\partial \bar{q}_{a}}{\partial x}\right)
$$

where $\bar{D}$ denotes the volume of deposited sediment per unit area and time and summed over all size fractions $\left(\bar{D}=\int_{-\infty}^{\infty}\right.$ $\left.\bar{D}_{e} d z\right)$, and $\bar{E}$ denotes volume of entrained sediment defined likewise. In equation (5) we recognize the commonly applied sediment continuity equation, where $\bar{q}_{a}$ denotes volume of bed load transport (excluding pores) per unit width and time averaged over a series of bed forms.

[10] In the sorting evolution model, we distinguish between three types of vertical sediment fluxes (also see Figure 2):

$$
\bar{D}_{e i}-\bar{E}_{e i}=\left.\left(\bar{D}_{e i}-\bar{E}_{e i}\right)\right|_{I}+\left.\left(\bar{D}_{e i}-\bar{E}_{e i}\right)\right|_{I I}+\left.\left(\bar{D}_{e i}-\bar{E}_{e i}\right)\right|_{I I I}
$$

where the three types of vertical sediment fluxes are type I, sediment fluxes through dune migration, i.e., grain sizeselective deposition down a bed form lee face and the variability in trough elevations; type II, sediment fluxes through a change in time of the PDF of relative trough elevations; and type III, sediment fluxes through net aggradation or degradation. For simplicity, we assume that these three types of vertical sorting fluxes do not interact with one another. This means, for instance, that when we consider sediment fluxes through bed form migration, both the PDF of relative trough elevations and the mean bed level are assumed to be steady. We describe the derivation of formulations for sediment fluxes through bed form migration (type I) in section 3.1, sediment fluxes due to time variation of the PDF of relative trough elevations (type II) in section 3.2, and sediment fluxes through net aggradation or degradation (type III) in section 3.3.

\subsection{PDF of Relative Trough Elevations}

[11] Application of the morphodynamic model system as presented in Figure 2 requires a submodel describing the adapted PDF of trough elevations relative to the mean bed level for a series of bed forms, indicating the probability density that the trough elevation equals $z$, weighted by the horizontal distance involved, $\tilde{p}_{b}$. The relative trough elevation, $\Delta_{b}$, is defined as the vertical distance between the mean bed level and the bed form trough elevation, $\eta_{b}$ (Figure 3). Van der Mark et al. [2005] propose a simple 
(a)

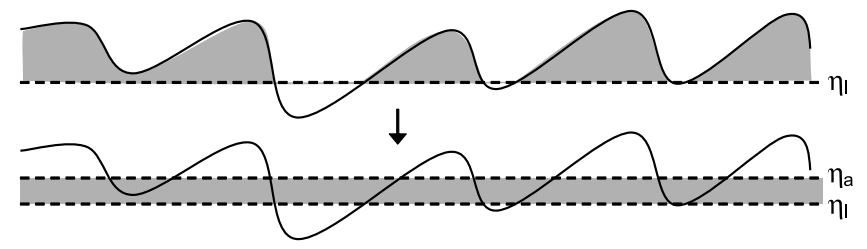

(b)

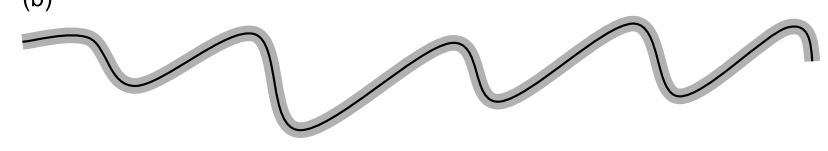

Figure 4. Calculating the mean composition of the bed surface when applying (a) the Hirano [1971] active layer model using equation (8) and (b) the sorting evolution model using equation (9). Figure 4 a (top) illustrates the part of the bed that contributes to calculating the composition of the active layer, whereas Figure 4a (bottom) illustrates the positioning of the active layer. The upper elevation of the active layer equals the mean bed level, $\bar{\eta}_{a}$, while the elevation of the interface between the active layer and the substrate, $\eta_{I}$, is determined by the thickness of the active layer, $\delta\left(\eta_{I}=\bar{\eta}_{a}-\delta\right)$.

model for the variation in relative trough elevations. On the basis of a number of data sets from flume experiments, they find that the standard deviation of the relative trough elevation, $\sigma \Delta_{b}$, is more or less a linear function of the mean value of the relative trough elevation, $\mu_{\Delta_{b}}$ :

$$
\sigma_{\Delta_{b}}=0.6 \mu_{\Delta_{b}}
$$

In other words, the deeper the mean trough elevation, the larger is the variation of the trough elevation around its mean value. Apparently, the variation of the trough elevation around its mean value is more or less independent of scale.

[12] This means that the PDF of relative trough elevations can be modeled using equation (7), in combination with a model for the time evolution of the mean relative trough elevation. Such a model, however, is not readily available. For the time being, we therefore propose to use a model for the time evolution of the bed form height averaged over a series of bed forms (i.e., the mean bed form height), $\bar{\Delta}$, using a bed form height model by, for instance, Gill [1971] or Van Rijn [1984], while assuming the mean relative trough elevation to be equal to half the mean bed form height $\left(\bar{\Delta}_{b}(t)=\right.$ $\left.\frac{1}{2} \bar{\Delta}(t)\right)$.

[13] Within the case study described in section 5, we use measured data rather than a submodel for the time evolution of the PDF of relative trough elevations.

\subsection{Bed Surface Composition}

[14] Being part of a morphodynamic model system, one of the main quantities a sediment continuity model needs to solve for is the time evolution of the mean bed surface composition (i.e., the volume fraction content of size fraction $i$ at the bed surface averaged over a series of bed forms), $\bar{F}_{\text {suri }}$. This important parameter is required as input for calculating the following parameters: the hydraulic roughness; the total rate of the bed load transport, $\bar{q}_{a}$ (and the volume fraction content of size fraction $i$ in the bed load transport, $\bar{F}_{a i}$ ); and the volume of suspended load transport of size fraction $i$ per unit width and time, $\bar{q}_{\text {suspi } i}$.

[15] When applying the Hirano [1971] active layer model, the mean bed surface composition, $\vec{F}_{\text {suri }}$, is assumed to be equal to the volume fraction content of size fraction $i$ in the active layer, $F_{m i}$ :

$$
\bar{F}_{\text {suri }}=F_{m i}
$$

When applying the sorting evolution model, in principle the mean composition of the bed surface, $\bar{F}_{\text {suri }}$, is defined as

$$
\bar{F}_{\text {suri }}=\int_{\eta_{m n}}^{\eta_{m x}} \bar{F}_{i} \bar{p}_{e} d z
$$

where $\eta_{m n}$ and $\eta_{m x}$ denote the lower and upper limits of the active part of the bed, respectively. Equation (9) implies that when applying the sorting evolution model $\bar{F}_{\text {suri }}$ is defined as the mean volume fraction content of size fraction $i$ at the actual bed surface, weighted over all bed elevations exposed to the flow. Figure 4 illustrates the fundamental difference between equations (8) and (9). One has to realize that the method to determine the mean composition of the bed surface needs to suit the specific submodels applied in calculating the hydraulic roughness, bed load and/or suspended load transport.

\subsection{Hydraulic Roughness}

[16] A submodel describing the hydraulic roughness is required for calculating its effect on the flow, as well as on bed load and suspended load transport.

[17] The part of the hydraulic roughness that is attributed to grains, i.e., skin friction, is obviously closely related to some measure of the composition of the bed surface, e.g., the mean bed surface composition, $\bar{F}_{\text {suri }}$. Existing models for skin friction, such as the one by Van Rijn [1984], are based on, for instance, the $d_{90}$ (i.e., the geometric grain size for which $90 \%$ of the sediment mixture is finer) of the bed surface, which can be determined from the mean bed surface composition, $\bar{F}_{\text {suri }}$.

[18] The part of the hydraulic roughness that is attributed to bed forms, i.e., form drag, seems to be closely related to the PDF of bed surface elevations, which characterizes the shape and irregularity of the bed forms. However, a model relating form drag to the PDF of bed surface elevations is not readily available.

[19] Within the case study described in this paper, we do not need a submodel for the hydraulic roughness as we use measured data for both the flow and the sediment transport.

\subsection{Flow}

[20] A submodel describing the flow is required for calculating its effect on hydraulic roughness, as well as on bed load and suspended load transport. To this end, one can apply the well-known shallow water equations or a simplified equation for steady flow, such as the formulation for a backwater curve.

[21] Within the case study described in this paper, we use measured data rather than a submodel for the flow. 


\subsection{Total Bed Load Transport Rate}

[22] In the present version of the sorting evolution model, the volume fraction content of size fractions in the bed load transport (indicated by the term composition) is computed by the sorting evolution model itself. This is explained in section 3.1. This notwithstanding, a submodel for the total rate of bed load transport averaged over a series of bed forms, $\bar{q}_{a}$, is required. A submodel computing this total rate of bed load transport usually requires information on the skin friction, some flow parameter (e.g., the dimensionless shear stress), and the mean bed surface composition.

[23] Within the case study described in this paper, we use measured data rather than a submodel for the total rate of bed load transport.

\subsection{Suspended Load Transport}

[24] The present version of the sorting evolution model is aimed at conditions dominated by bed load transport. Yet, suspended load transport may be incorporated by taking the following steps: (1) calculate the mean composition of the bed surface, $\bar{F}_{\text {suri }}$, using equation (9); (2) neglect the interaction between vertical sediment fluxes through bed load transport and suspended load transport; and (3) use a model for the volume of suspended load transport of size fraction $i$ per unit width and time, $\bar{q}_{\text {suspi }}$, from the mean bed surface composition, $\bar{F}_{\text {suri }}$, and flow parameters:

$$
\bar{q}_{\text {suspi }}=f_{\text {susp }}\left(\bar{F}_{\text {suri }}, \text { flow parameters }\right)
$$

in which $f_{\text {susp }}$ represents a grain size-selective model for suspended load transport of nonuniform sediment.

[25] Suspended load transport did not occur in the case study considered in this paper, and therefore the proposed method is not tested.

\section{Sorting Evolution Model in Detail}

\subsection{Sediment Fluxes Through Dune Migration (Type I)}

[26] In the derivation of formulations for sediment fluxes through dune migration (type I), we assume the PDF of relative trough elevations, $\tilde{p}_{b}$, to be steady, as well as the mean bed level, $\bar{\eta}_{a}$ (also see section 2.1). This implies that the probability distribution of bed surface elevations relative to the mean bed level, $\tilde{P}_{s}$, and the probability distribution of bed surface elevations, $\bar{P}_{s}$, are steady, as well. The fundamental sediment continuity equations, i.e., equations (3)(5) now reduce to

$$
\begin{gathered}
c_{b} \bar{P}_{S} \frac{\partial \bar{F}_{i}}{\partial t}=\left.\left(\bar{D}_{e i}-\bar{E}_{e i}\right)\right|_{I} \\
0=\left.\left(\bar{D}_{e}-\bar{E}_{e}\right)\right|_{I} \\
0=\left.(\bar{D}-\bar{E})\right|_{I}
\end{gathered}
$$

[27] In the derivation of formulations for sediment fluxes through dune migration, we consider simultaneous entrainment and deposition fluxes over the stoss face of a bed form, but only deposition fluxes over the lee face (Figure 3):

$$
\begin{gathered}
\left.\bar{E}_{e i}\right|_{I}=\bar{E}_{e i s} \\
\left.\bar{D}_{e i}\right|_{I}=\bar{D}_{e i s}+\bar{D}_{e i l}
\end{gathered}
$$

where the subscript $s$ indicates the stoss face and the subscript $l$ indicates the lee face. The derivation of formulations for the overall entrainment and deposition densities for the stoss face, $\bar{E}_{\text {eis }}$ and $\bar{D}_{\text {eis }}$, and for the lee face, $\bar{D}_{\text {eil }}$, continues from the analysis by Blom and Parker [2004], which is summarized here.

[28] They introduce the parameter $E_{\text {siu }}$ as the volume of sediment of size fraction $i$ locally entrained from the stoss face, per unit area and time. In the parameter $E_{\text {siu }}$ the subscript $u$ indicates the case that only sediment of size fraction $i$ would be present, although hiding exposure effects may be included. The weighted entrainment rate $E_{s i}(x)$ denotes the volume of sediment of size fraction $i$ locally entrained from the stoss face, per unit area and time:

$$
E_{s i}(x)=E_{\text {siu }}(x) F_{i}(x)
$$

Note that $F_{i}$ at a certain elevation of the active part of the bed $z$ is assumed to be valid within the dunes, as well as at the bed surface. The weighted deposition rate $D_{s i}$ denotes the volume of sediment of size fraction $i$ locally deposited onto the stoss face per unit area and time at $x$ equals the weighted entrainment rate of this size fraction one step length upstream of $x$ :

$$
D_{s i}(x)=E_{s i}\left(x-\Lambda_{i}\right)=E_{s i u}\left(x-\Lambda_{i}\right) F_{i}\left(x-\Lambda_{i}\right)
$$

where the Einstein [1950] step length of size fraction $i, \Lambda_{i}$, is given by $\Lambda_{i}=\alpha d_{i}$ (Figure 3), where $\alpha$ denotes the dimensionless step length and $d_{i}$ denotes the geometric grain size of size fraction $i$.

[29] Blom and Parker [2004] derive the following expressions for the entrainment and deposition densities averaged over a series of irregular bed forms:

$$
\begin{aligned}
\bar{E}_{e i s}(z)= & \int_{\eta_{b \min }}^{\eta_{b \max }} \frac{\lambda_{s}}{\lambda} p_{\text {se }}(z) E_{\text {siu }}(z) \bar{F}_{i}(z) \tilde{p}_{b} d \eta_{b} \\
\bar{D}_{\text {eis }}(z)= & \int_{\eta_{\text {min }}}^{\eta_{b \max }} \frac{\lambda_{s}}{\lambda} p_{\text {se }}(z) E_{\text {siu }}\left(z-\eta_{\text {stepi }}(z)\right) \\
& \cdot \bar{F}_{i}\left(z-\eta_{\text {stepi }}(z)\right) \tilde{p}_{b} d \eta_{b} \\
\bar{D}_{\text {eil }}(z)= & \int_{\eta_{\text {bmin }}}^{\eta_{b \max }} \frac{\lambda_{l}}{\lambda} p_{\text {le }}(z) D_{l} F_{\text {leeloci }}(z) \tilde{p}_{b} d \eta_{b}
\end{aligned}
$$

where $\lambda$ denotes the bed form length, $\lambda_{s}$ and $\lambda_{l}$ denote the horizontal length of the bed form stoss and lee faces, respectively, $p_{s e}$ and $p_{l e}$ denote the probability density functions of bed surface elevations for an individual stoss 
and lee face, respectively, $\eta_{\text {stepi }}$ denotes the step length in $\mathrm{z}$ direction at elevation $z$ on the stoss face for size fraction $i$ (Figure 3), $D_{l}$ denotes the volume of sediment deposited onto the lee face per unit area and time (i.e., the deposition rate at the lee face), $F_{\text {leeloci }}$ denotes the volume fraction content of size fraction $i$ in the sediment deposited at elevation $z$ at the lee face, $\tilde{p}_{b}$ denotes the adapted PDF of trough elevations relative to the mean bed level for a series of bed forms, indicating the probability density that the trough elevation equals $z$, weighted by the horizontal distance involved (i.e., PDF of relative trough elevations), $\eta_{b}$ denotes the trough elevation, $\eta_{b \max }$ denotes the highest bed form trough elevation, and $\eta_{\text {bmin }}$ denotes the lowest bed form trough elevation. Note that the integral in these equations denotes the procedure of averaging over all trough elevations.

[30] The deposition rate at the lee face, $D_{l}$, and the volume fraction content of size fraction $i$ in the sediment deposited at the lee face, $F_{\text {leeloci }}$, are given by

$$
\begin{gathered}
D_{l}=q_{\text {top }} / \lambda_{l} \\
F_{\text {leeloci }}=F_{\text {topi }} \omega_{i}
\end{gathered}
$$

where $q_{\text {top }}$ denotes the volume of bed load transport at the bed form crest per unit width and time (excluding pores), and $F_{\text {topi }}$ denotes the volume fraction content of size fraction $i$ in the bed load transport at the bed form crest $\left(F_{\text {topi }}=q_{\text {topi }} / q_{\text {top }}\right)$. The lee sorting function, $\omega_{i}$, specifies to what extent a specific size fraction that is transported over the bed form crest is deposited at a certain elevation of the lee face (Appendix A).

[31] For simplicity, we now assume the bed forms to have a triangular shape with varying trough elevations, so that for each bed form the probability density that the bed surface elevation equals $z, p_{e}$, is given by

$$
p_{e}=p_{s e}=p_{l e}=J / \Delta
$$

where $J$ is a Heaviside step function which equals 1 if elevation $\mathrm{z}$ is covered by the bed form, and $J$ equals 0 if elevation $z$ is outside the range of elevations covered by the specific bed form (see Appendix A). Note that equation (23) does not imply that the slope of the stoss face is equal to the slope of the lee face. Also we assume the mean bed load transport rate to be identical for each bed form in the series of bed forms $\left(q_{a}=\bar{q}_{a}\right)$, and we impose the composition of the sediment transported over each crest to be the same $\left(F_{\text {topi }}=\bar{F}_{\text {topi }}\right)$. Finally, we make no distinction in sorting between bed forms within one series of bed forms $\left(F_{i}=\bar{F}_{i}\right)$.

[32] Now, in order to find a solution to the time evolution of the vertical sorting profile of nonuniform sediment, $\bar{F}_{i}$, we need to solve equations (11) and (12). Since the probability distribution of bed surface elevations, $\bar{P}_{s}$, is steady, the total amount of sediment at each elevation is steady, as well. This is satisfied when the total amount of sediment entrained from the bed at elevation $z$ : (1) is independent of the local bed composition $\bar{F}_{i}(z)$; (2) is independent of the bed surface elevation $z$; and (3) has a composition equal to the local bed composition $\bar{F}_{i}(z)$. These constraints are satisfied when the following equation is met for each individual bed form:

$$
E_{\text {snet }} \bar{F}_{i}(z)=E_{\text {siu }}(z) \bar{F}_{i}(z)-E_{\text {siu }}\left(z-\eta_{\text {stepi }}\right) \bar{F}_{i}\left(z-\eta_{\text {stepi }}\right)
$$

where $E_{s}$ net denotes the net entrained volume of all size fractions on the stoss face per unit area and time, which can be written as

$$
E_{\text {snet }}=q_{\text {top }} / \lambda_{s}
$$

Herein the total bed load transport rate over the bed form crest, $q_{\text {top }}$, is twice the overall total bed load transport rate, $\bar{q}_{a}$ :

$$
q_{t o p}=\bar{q}_{t o p}=2 \bar{q}_{a}
$$

which can be found when applying the simple wave equation to the migration of triangular bed forms [Bagnold, 1941]. Hence, also the bed load transport rate over the bed form crest is the same for each individual bed form.

[33] With equations (12), (14)-(15), (18)-(21), and (23)-(26), equation (11) now reduces to a relaxation-type sorting evolution model:

$$
\frac{\partial \bar{F}_{i}}{\partial t}=\frac{2 \bar{q}_{a}}{c_{b} \bar{P}_{s}} \int_{\eta_{b \min }}^{\eta_{b \max }} \frac{p_{e}}{\lambda}\left[F_{\text {leeloci }}-\bar{F}_{i}\right] \tilde{p}_{b} d \eta_{b}
$$

The term relaxation here indicates that the system has an equilibrium state and returns to its equilibrium state after a disturbance. Equation (27) shows that equilibrium is reached when the overall composition of the sediment deposited at elevation $z$ at the lee face equals the composition of the bed at that elevation. The timescale of the adaptation of the sorting profile is considered in section 4. Note that $\lambda, p_{e}, F_{\text {leeloci }}$, and $\tilde{p}_{b}$ in equation (27) all depend on the specific trough elevation $\eta_{b}$. The geometric properties of the individual triangular dunes are described by the following simple rules. Each crest is assumed to have the same absolute distance to the mean bed level as its trough, and the steepness of the lee faces is assumed to equal the angle of repose $(\nu)$. The dune length is assumed to be proportional to the dune height and the ratio of the mean dune length $\bar{\lambda}$ to the mean dune height $\bar{\Delta}$ :

$$
\begin{gathered}
\Delta=2 \Delta_{b} \\
\lambda=(\bar{\lambda} / \bar{\Delta}) \Delta \\
\lambda_{l}=\Delta / \tan (\nu) \\
\lambda_{s}=\lambda-\lambda_{l}
\end{gathered}
$$

see also Figure 3. Note that equations (28) through (30) are not supposed to be generally valid and their applicability should be checked against data when applying them. 
[34] A solution to equation (27) wherein $F_{\text {leeloci }}$ is given by (22) requires a formulation for the volume fraction content of size fraction $i$ in the sediment transported over the bed form crest, $F_{\text {topi }}=\bar{F}_{\text {topi }}$ :

$$
\bar{F}_{\text {topi }}=\frac{1}{\bar{E}_{\text {snet }}} \int_{\eta_{b \min }}^{\eta_{b \max }} E_{\text {snet }} \int_{\eta_{b}}^{\eta_{t}} \bar{F}_{i} p_{e} d z \tilde{p}_{b} d \eta_{b}
$$

where $\bar{E}_{\text {snet }}$ denotes net entrained volume of all size fractions on the stoss face, per unit area and time, averaged over a series of bed forms, and $\eta_{t}$ denotes the bed form crest elevation. The inner integral in equation (32) expresses the condition that the volume fraction content of size fraction $i$ transported over an individual crest is equal to the integral over bed elevations of the vertical sorting profile multiplied by its PDF of bed surface elevations, $p_{e}$. This is true since the net entrainment rate over the bed form stoss face, $E_{\text {snet }}$, is uniform over all bed surface elevations, and the composition of the net entrainment at elevation $z$ is assumed to be equal to the bed composition at that elevation, $\bar{F}_{i}$. To find the overall composition of sediment transported over the bed form crest, $\bar{F}_{\text {topi }}$, the composition of the sediment transported over an individual crest is averaged over all trough elevations while weighted by its probability density of occurrence, $\tilde{p}_{b}$. The overall net entrainment rate, $\bar{E}_{\text {snet }}$, equals

$$
\bar{E}_{\text {snet }}=\int_{\eta_{b \min }}^{\eta_{b \max }} E_{\text {snet }} \tilde{p}_{b} d \eta_{b}
$$

[35] Similar to the formulation for the overall composition of sediment transported over the bed form crest, $\bar{F}_{\text {topi }}$, the volume fraction content of size fraction $i$ in the bed load transport at the stoss face at elevation $z$, averaged over a series of bed forms, $\bar{F}_{q s i}$, is given by

$$
\bar{F}_{q s i}(z)=\frac{1}{\hat{E}_{\text {snet }}(z)} \int_{\eta_{b \min }}^{\eta_{b \max }} \frac{E_{\text {snet }}}{\int_{\eta_{b}}^{z} p_{e} d z} \int_{\eta_{b}}^{z} \bar{F}_{i} p_{e} d z \tilde{p}_{b} d \eta_{b}
$$

where the net entrained volume of all size fractions on the stoss face at elevation $z$, per unit area and time, averaged over a series of bed forms, $\hat{E}_{\text {snet }}$, is given by

$$
\hat{E}_{\text {snet }}(z)=\int_{\eta_{b \min }}^{\eta_{b \max }} J(z) E_{\text {snet }} \tilde{p}_{b} d \eta_{b}
$$

Now, the volume fraction content of size fraction $i$ in the bed load transport, averaged over a series of bed forms (i.e., the bed load transport composition), $\bar{F}_{a i}$, is found by averaging the grain size-specific and elevation-specific bed load transport rate, $\bar{F}_{q s i}$, over all elevations of the active bed:

$$
\bar{F}_{a i}=\int_{\eta_{m n}}^{\eta_{m x}} \bar{F}_{q s i} \bar{p}_{e} d z
$$

Note that in equation (36), for simplicity, the contribution of the composition of the bed load transport over the lee face has been neglected, as the horizontal length of the lee face is much shorter than the length of the stoss face.
[36] For a series of regular bed forms, equations (27) and (32) reduce to

$$
\frac{\partial \bar{F}_{i}}{\partial t}=\frac{2 \bar{q}_{a} \bar{p}_{e}}{c_{b} \bar{P}_{s} \bar{\lambda}}\left[\bar{F}_{\text {leeloci }}-\bar{F}_{i}\right]
$$

and

$$
\bar{F}_{\text {topi }}=\int_{\eta_{b}}^{\eta_{t}} \bar{F}_{i} \bar{p}_{e} d z
$$

[37] Thus, the set of equations derived in the present section computes the time evolution of both the vertical sorting profile and volume fraction contents of size fractions in the bed load transport resulting from the migration of a series of dunes. The equations require the following input parameters: the initial sorting profile; the time evolution of the PDF of relative trough elevations, $\tilde{p}_{b}$; the time evolution of the total bed load transport rate, $\bar{q}_{a}$ (not its composition); and the ratio of the mean bed form length to the mean bed form height, $\bar{\lambda} / \bar{\Delta}$.

\subsection{Sediment Fluxes Through Unsteady Bed Form Dimensions (Type II)}

[38] Bed form dimensions, and therefore the PDF of relative trough elevations, vary in time with changing hydraulic conditions. For instance, during a flood event the increase in bed shear stress may cause bed form crests to become higher and troughs to become deeper, while the mean bed level may remain steady. Such a change in time of the PDF of relative trough elevations, $\tilde{p}_{b}$, results from net entrainment and deposition fluxes from and to bed surface elevations. As mentioned in section 2.1, we simply assume these fluxes to be independent of the sediment fluxes through both dune migration and net aggradation or degradation. In other words, when the PDF of relative trough elevations, $\tilde{p}_{b}$, changes in time, the mean bed level is assumed to be steady and vertical sediment fluxes through bed form migration are assumed to be negligible.

[39] As described in section 2.2, at each time step we need to predict the PDF of relative trough elevations, $\tilde{p}_{b}$, using an external submodel. Having predicted $\tilde{p}_{b}$ at the new time step $t_{2}$, we can determine the probability distribution of bed surface elevations at the new time step, $\bar{P}_{s}\left(t_{2}\right)$, from

$$
\bar{P}_{s}=1-\int_{-\infty}^{z} \bar{p}_{e} d z
$$

where the PDF of bed surface elevations, $\bar{p}_{e}$, depends on the PDF of relative trough elevations as follows:

$$
\bar{p}_{e}=\int_{\eta_{b \min }}^{\eta_{b \max }} \frac{J}{\Delta} \tilde{p}_{b} d \eta_{b}
$$

[40] Figure 5 illustrates how at elevations where $\bar{P}_{s}\left(t_{2}\right)>$ $\bar{P}_{s}\left(t_{1}\right)$, sediment has been deposited. At elevations where $\bar{P}_{s}$ $\left(t_{2}\right)<\bar{P}_{s}\left(t_{1}\right)$, on the other hand, sediment has been entrained. We simply assume that sediment entrained from bed surface elevation $z$ has the same composition as what is present at that elevation. We can now determine the volume fraction content of size fraction $i$ in the total amount of 


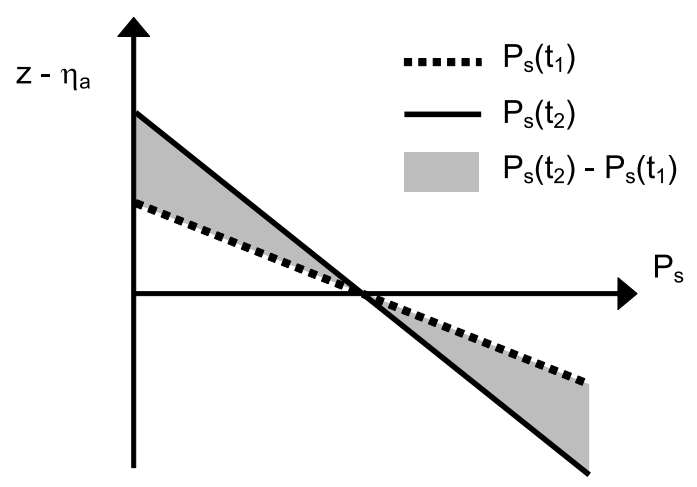

Figure 5. Example of how the probability distribution of bed surface elevations, $\bar{P}_{s}$, can change in time.

sediment entrained from the bed due to a change in time of the PDF of relative trough elevations, averaged over a series of bed forms, $\bar{F}_{P i}$ :

$$
\begin{aligned}
\bar{F}_{P i} & =\frac{\int_{\eta_{m n}}^{\eta_{m x}} I(z)\left[\bar{C}_{i}\left(t_{1}\right)-\bar{C}_{i}\left(t_{2}\right)\right] d z}{\int_{\eta_{m n}}^{\eta_{m x}} \sum_{i}^{N} I(z)\left[\bar{C}_{i}\left(t_{1}\right)-\bar{C}_{i}\left(t_{2}\right)\right] d z} \\
= & \frac{\int_{\eta_{m n}}^{\eta_{m x}} I(z)\left[\bar{P}_{s}\left(t_{1}\right)-\bar{P}_{s}\left(t_{2}\right)\right] \bar{F}_{i}\left(t_{1}\right) d z}{\int_{\eta_{m n}}^{\eta_{m x}} I(z)\left[\bar{P}_{s}\left(t_{1}\right)-\bar{P}_{s}\left(t_{2}\right)\right] d z}
\end{aligned}
$$

where $\eta_{m n}$ and $\eta_{m x}$ denote the lower and upper levels of the active bed at either time $t_{1}$ or $t_{2}$, that is, when the active bed covers the widest range of bed elevations, and where

$$
I(z)= \begin{cases}1 & \text { if } \bar{P}_{s}\left(t_{2}\right) \leq \bar{P}_{s}\left(t_{1}\right) \\ 0 & \text { if } \bar{P}_{s}\left(t_{2}\right)>\bar{P}_{s}\left(t_{1}\right)\end{cases}
$$

where $I$ denotes a Heaviside step function which equals 1 if at elevation $\mathrm{z}$ sediment has been entrained, and as such the amount of sediment at elevation $\mathrm{z}$ has decreased (represented by $\left.\bar{P}_{s}\left(t_{2}\right) \leq \bar{P}_{s}\left(t_{1}\right)\right)$. Otherwise $I$ equals 0 .

[41] At elevations where bed material is entrained (represented by $\left.\bar{P}_{s}\left(t_{2}\right) \leq \bar{P}_{s}\left(t_{1}\right)\right)$, the bed composition does not change in time. At elevations where deposition occurs (represented by $\bar{P}_{s}\left(t_{2}\right)>\bar{P}_{s}\left(t_{1}\right)$ ), the composition of the deposited sediment is assumed to be equal to the mean composition of the total amount of sediment entrained from the bed, $\bar{F}_{P i}$. At the new time step, the bed composition at such an elevation can then be determined by weighting the original bed material present at this elevation and the deposited sediment. The bed composition at the new time step thus equals

$$
\begin{aligned}
& \bar{F}_{i}\left(t_{2}\right)=\bar{F}_{i}\left(t_{1}\right) \\
& \bar{F}_{i}\left(t_{2}\right)=1 / \bar{P}_{s}\left(t_{2}\right)\left[\bar{P}_{s}\left(t_{1}\right) \bar{F}_{i}\left(t_{1}\right)\right. \\
& \left.+\left(\bar{P}_{s}\left(t_{2}\right)-\bar{P}_{s}\left(t_{1}\right)\right) \bar{F}_{P i}\right] \\
& \text { if } \quad \bar{P}_{s}\left(t_{2}\right) \leq \bar{P}_{s}\left(t_{1}\right) \\
& \text { if } \quad \bar{P}_{s}\left(t_{2}\right)>\bar{P}_{s}\left(t_{1}\right)
\end{aligned}
$$

[42] Thus, the proposed method accounts for the effect of a change in time of the PDF of relative trough elevations on the vertical sorting profile. Note that the time evolution of the PDF of relative trough elevations itself is computed using an external submodel. The method described here is a rather artificial one that simplifies the actual physical processes. For instance, the method does not incorporate grain size-selective processes. In reality, however, grain size-selective processes surely play a role. For instance, the winnowing of fines from the trough surface and subsurface may cause the coarse bed layer below migrating bed forms to subside and the range of elevations of the active bed to gradually increase.

\subsection{Sediment Fluxes Through Net Aggradation or Degradation (Type III)}

[43] Divergences in bed load and/or suspended load transport result in net aggradation or degradation of the river bed. In this section, it is explained how we calculate the net aggradation or degradation of the river bed and the change in the vertical sorting profile through the resulting sediment fluxes. We also refer to the type III sediment fluxes in Figure 2.

[44] In order to include net aggradation or degradation in the sorting evolution model, we make a number of assumptions. As mentioned in section 2.1, we neglect the interaction among vertical sediment fluxes through type I, bed form migration; type II, a change in time of the PDF of relative trough elevations; and type III, net aggradation or degradation. Furthermore, we neglect the interaction between vertical sediment fluxes through divergences in bed load transport and those through suspended load transport. The fundamental equations (3)-(5) now yield

$$
\begin{gathered}
c_{b} \bar{P}_{s} \frac{\partial \bar{F}_{i}}{\partial t}+c_{b} \bar{F}_{i} \bar{p}_{e} \frac{\partial \bar{\eta}_{a}}{\partial t}=\left.\left(\bar{D}_{e i}-\bar{E}_{e i}\right)\right|_{I I I} \\
c_{b} \bar{p}_{e} \frac{\partial \bar{\eta}_{a}}{\partial t}=\left.\left(\bar{D}_{e}-\bar{E}_{e}\right)\right|_{I I I} \\
c_{b} \frac{\partial \bar{\eta}_{a}}{\partial t}=\left.(\bar{D}-\bar{E})\right|_{I I I}=-\frac{\partial\left(\bar{q}_{a}+\bar{q}_{\text {susp }}\right)}{\partial x}
\end{gathered}
$$

where $\bar{q}_{\text {susp }}$ denotes the volume of suspended load transport per unit width and time, averaged over a series of bed forms. Note that from equation (46) we can predict the change in time of the mean bed level. We now assume the vertical sediment fluxes through net aggradation or degradation to be distributed over bed elevations according to their exposure to the flow, whence the bed elevationspecific entrainment and deposition fluxes are given by

$$
\left.\left(\bar{D}_{e}-\bar{E}_{e}\right)\right|_{I I I}=-\bar{p}_{e} \frac{\partial\left(\bar{q}_{a}+\bar{q}_{\text {susp }}\right)}{\partial x}
$$

Furthermore, we assume the composition of the vertical sediment fluxes through net aggradation or degradation to be independent of bed surface elevation, so that the grain size-specific and bed elevation-specific entrainment and deposition fluxes are given by

$$
\left.\left(\bar{D}_{e i}-\bar{E}_{e i}\right)\right|_{I I I}=-\bar{p}_{e} \frac{\partial\left(\bar{q}_{a i}+\bar{q}_{s u s p i}\right)}{\partial x}
$$

This assumption that the composition of the vertical sediment fluxes through net aggradation or degradation is independent of bed surface elevation is not necessarily true. Present research by the first author is aimed at investigating 


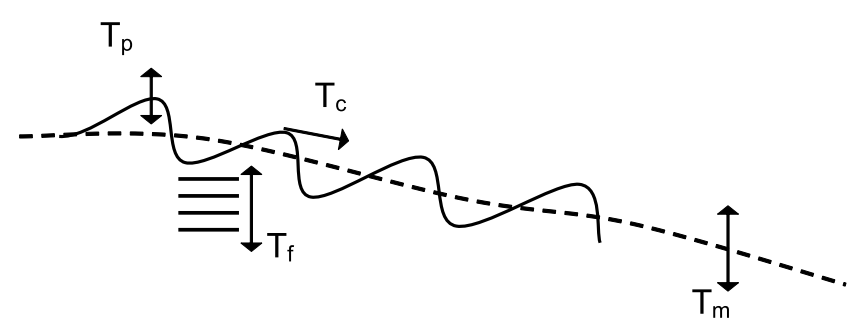

Figure 6. Timescales involved when applying the sorting evolution model in a morphodynamic model system: (1) the timescale of dune migration, $T_{c},(2)$ the timescale of adaptation of dune dimensions, $T_{p}$, (3) the timescale of vertical sorting, $T_{f}(z)$, and (4) the timescale of large-scale morphodynamic changes, $T_{m}$.

to what degree this assumption is justified. Combination of equations (44) and (48) yields

$$
\frac{\partial \bar{F}_{i}}{\partial t}=-\frac{\bar{p}_{e}}{c_{b} \bar{P}_{s}}\left(\frac{\partial\left(\bar{q}_{a i}+\bar{q}_{s u s p i}\right)}{\partial x}+c_{b} \bar{F}_{i} \frac{\partial \bar{\eta}_{a}}{\partial t}\right)
$$

where the change in mean bed level, $\partial \bar{\eta}_{a} / \partial t$, is calculated from equation (46).

[45] Thus, equation (49) allows us to compute the effect of net aggradation or degradation upon the vertical sorting profile. Please note, however, that the main purpose of the formulations as proposed in sections $3.1-3.3$ is to take into account the effects of grain size-selective transport and vertical sorting in the computation of net aggradation or degradation of the river bed.

\section{Timescales}

[46] When applying the sorting evolution model in a morphodynamic model system, we can distinguish the following timescales (Figure 6) (1) timescale of dune migration, $T_{c}$; (2) timescale of adaptation of dune dimensions, $T_{p}$; (3) timescale of vertical sorting, $T_{f}$; and (4) timescale of large-scale morphodynamic changes, $T_{m}$.

[47] The timescale of dune migration, $T_{c}$, is defined as the time required for a bed form to migrate over a distance equal to its mean bed form length, $\bar{\lambda}$ :

$$
T_{c}=\bar{\lambda} / \bar{c}
$$

where, according to Bagnold's [1941] application of the simple wave approach to dune migration, the bed form migration speed averaged over a series of bed forms, $\bar{c}$, can be written as

$$
\bar{c}=\frac{\bar{q}_{t o p}}{c_{b} \bar{\Delta}}=\frac{2 \bar{q}_{a}}{c_{b} \bar{\Delta}}
$$

[48] Since all parameters in the sorting evolution model are averaged over a series of bed forms, sediment deposited at elevation $z$ is assumed to be mixed immediately with all material present at this elevation. This implies that, in order to apply the sorting evolution model, it is required that the timescale of dune migration is much smaller than the timescales of adaptation of dune dimensions, vertical sorting, and morphodynamic changes:

$$
T_{c} \ll \min \left\{T_{p}, T_{f}, T_{m}\right\}
$$

This is consistent with the description of large-scale morphodynamic changes in many existing morphodynamic model systems. Namely, in order to use our common sediment transport models, which are derived for steady conditions, it is required that the timescale of morphodynamic changes is much larger than the one of dune migration:

$$
T_{c} \ll T_{m}
$$

Likewise, in order to use models for hydraulic roughness, bed form height, and bed form length, which are mostly valid for steady conditions, it is required that the timescale of adaptation of dune dimensions is larger than the one of dune migration, and that the timescale of morphodynamic changes is larger than the one of adaptation of dune dimensions:

$$
\begin{aligned}
& T_{c} \ll T_{p} \\
& T_{p} \ll T_{m}
\end{aligned}
$$

Let us now consider the relation between the sorting timescale, $T_{f}$, and the timescale of adaptation of dune dimensions, $T_{p}$. It seems that the latter is either smaller than the sorting time scale $\left(T_{p} \ll T_{f}\right)$ or of the same order of magnitude $\left(T_{p} \simeq T_{f}\right)$. In conditions with high bed shear stresses that are well above the critical bed shear stresses of all grain sizes in the mixture, deeper bed layers that are reached by the flow only occasionally slowly change in composition. The PDF of bed surface elevations may have reached equilibrium much faster $\left(T_{p} \ll T_{f}\right)$. This was the case in, for instance, flume experiment B2 by Blom et al. [2003]. However, in conditions with relatively low bed shear stresses and widely graded sediment mixtures that are predominated by partial transport (i.e., the coarsest size fractions are not or barely in transport), the time evolution of the PDF of bed surface elevations is directly related to the time evolution of the sorting profile $\left(T_{p} \simeq T_{f}\right)$. Coarse bed layers may develop that hinder the entrainment of bed material and thus the growth of bed forms. Fine sediment may be winnowed from below a coarse bed layer, which may result in a very slow adaptation of the bed form height. This was the case in, for instance, flume experiments A1 and B1 by Blom et al. [2003].

[49] Equation (27) describes the time evolution of sorting through dune migration for a series of irregular dunes. It is a relaxation-type equation, but a formulation for the timescale of the adaptation of sorting is not straightforward. This is due to the fact that most parameters in equation (27) depend on time and the trough elevation, $\eta_{b}$. Yet, under the assumptions that net aggradation or degradation is negligible, the PDF of relative trough elevations is steady, the total bed load transport rate is steady, and the composition of the sediment transported over the crest is steady, the timescale of the adaptation of sorting is seen to be of the order of 

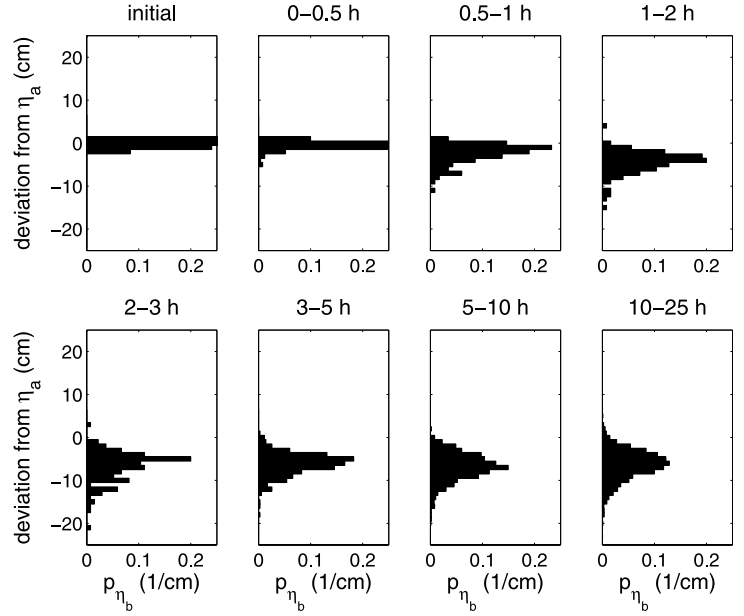

Figure 7. Measured time evolution of the PDF of relative trough elevations, $\tilde{p}_{\eta_{b}}$, for experiment $\mathrm{B} 2$.

$$
T_{f}(z)=\frac{\bar{\lambda}}{2 \bar{q}_{a}} \frac{c_{b} \bar{P}_{s}(z)}{\bar{p}_{e}(z)}
$$

Equation (52) tells us that (1) the larger the relative amount of sediment at bed elevation $z$ (represented by $c_{b} \bar{P}_{s}$ ), the slower is the adaptation of sorting; (2) the larger the exposure to the flow of elevation $z$ (represented by $\bar{p}_{e}$ ), the faster is the adaptation of sorting; (3) the larger the mean bed form length, $\bar{\lambda}$, the slower is the adaptation of sorting; namely, the larger the mean bed form length, $\bar{\lambda}$, the smaller is the amount of bed forms over some fixed distance, and the smaller are the entrainment and deposition rates; and (4) the larger the total bed load transport rate, $\bar{q}_{a}$, the faster is the adaptation of sorting.

[50] Note that the timescale of vertical sorting, $T_{f}$, is a function of bed elevation $z$. At deeper elevations of the active bed the bed composition adjusts more slowly to changing conditions than at higher bed elevations. This is due to (1) the very low elevations of the active bed being reached by the flow only occasionally (represented by a small value of $\bar{p}_{e}$ ), and (2) more bed material being present at lower bed elevations than at higher elevations (represented by a large value of $c_{b} \bar{P}_{s}$ ).

[51] When the timescale of morphodynamic changes, $T_{m}$, is of the same order of magnitude as the ones of adaptation of dune dimensions, $T_{p}$ and vertical sorting, $T_{f}$, we need to take into account the time evolution of both the adaptation of dune dimensions and the vertical sorting profile when computing changes in morphodynamics. The sorting evolution model is particularly appropriate for this purpose.

[52] A special situation occurs when the timescale of morphodynamic changes is much larger than the sorting timescale and the time scale of adaptation of dune dimensions:

$$
T_{m} \gg \max \left\{T_{p}, T_{f}\right\} \quad \min \left\{T_{p}, T_{f}\right\} \gg T_{c}
$$

If, in this case, one is interested in processes at the timescale of morphodynamic changes, $T_{m}$, we may assume that the PDF of relative trough elevations, $\tilde{p}_{b}$, and the vertical sorting profile, $\bar{F}_{i}$, have reached a state of quasi-equilibrium at every point in time. In these quasi-equilibrium conditions, we may apply equilibrium similarity profiles for the PDF of relative trough elevations $\tilde{p}_{b}$, and the sorting profile, $\bar{F}_{i}$. In such a case, the equilibrium sorting model [Blom et al., 2006] can be applied instead of the sorting evolution model.

\section{Application of the New Model}

[53] The verification of the sorting evolution model is based on a comparison between the measured and computed grain size-selective transport and vertical sorting profiles for flume experiments B2 and A2 by Blom et al. [2003]. Flume experiments $\mathrm{B} 2$ and $\mathrm{A} 2$ qualify for this purpose as application of the sorting evolution model should be limited to situations in which the bed is fully covered by bed forms. During the experiments uniform conditions were maintained and the transported sediment was recirculated. As a result net aggradation or degradation did not occur. The sediment transport consisted solely of bed load transport.

\subsection{Reduced Morphodynamic Model System}

[54] In the flume experiments no net degradation or degradation occurred. In other words, the mean bed level remained steady and sediment fluxes through net aggradation or degradation (type III) were negligible.

[55] In the present case study, measured values for the PDF of relative trough elevations are used as input. A submodel predicting the time evolution of the PDF of relative trough elevations (section 2.2) is therefore not required. Figures 7 and 8 show the measured time evolution of the PDF of trough elevations relative to the mean bed level for a series of bed forms, indicating the probability density that the trough elevation equals $z, \tilde{p}_{\eta b}$, for experiments B2 and A2. The largest changes in the PDF of relative trough elevations occur within 0 to 2 flow hours, and after that only small changes occur. Measured trough elevations above the mean bed level have been neglected, because of the way bed forms are schematized (i.e., having a triangular shape with trough elevation at the same distance below the mean bed level as the crest elevation is located above it). We account for the time evolution of the PDF of relative trough elevations by following the procedure de-
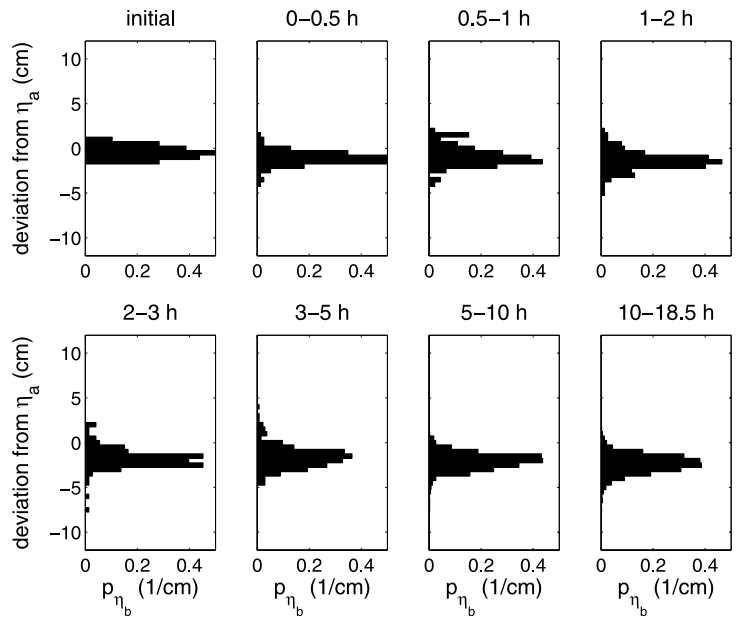

Figure 8. Measured time evolution of the PDF of relative trough elevations, $\tilde{p}_{\eta_{b}}$, for experiment $\mathrm{A} 2$. 
Table 1. List of Input and Output Parameters of the Morphodynamic Model System for Both a Regular Application and This Specific Case Study ${ }^{\mathrm{a}}$

\begin{tabular}{|c|c|c|}
\hline Computation & Input Parameters & Output Parameters \\
\hline regular application & $\begin{array}{l}\text { total rate of bed load transport (submodel) } \\
\text { PDF of relative trough elevations (submodel) } \\
\text { initial sorting profile (measured/estimated) } \\
\text { ratio mean dune length to height (submodel) }\end{array}$ & $\begin{array}{r}\text { net aggradation or degradation } \\
\text { vertical sorting profile } \\
\text { volume fractions in bed load }\end{array}$ \\
\hline this case study & $\begin{array}{r}\text { net aggradation or degradation } \\
\text { total rate of bed load transport (measured) } \\
\text { PDF of relative trough elevations (measured) } \\
\text { initial sorting profile (measured) } \\
\text { ratio mean dune length to height (measured) }\end{array}$ & $\begin{array}{l}\text { vertical sorting profile } \\
\text { volume fractions in bed load }\end{array}$ \\
\hline
\end{tabular}

${ }^{\mathrm{a}}$ All listed parameters represent parameters averaged over a series of bed forms.

scribed in section 3.2. At each transition between the phases shown in Figures 7 and 8, we impose a change in time of the PDF of relative trough elevations.

[56] Table 1 shows the list of input and output parameters for both a regular application and this case study. In the case study we use measured values for the overall hydraulic roughness and the overall total rate of bed load transport as input to the model computations. Submodels predicting the mean bed surface composition and the flow, which are usually required for predicting hydraulic roughness and bed load transport, are therefore not required. The method for including suspended load transport as proposed in section 2.7 has not been used and tested, as suspended load transport did not occur in the flume experiments. Note that, in a regular application, the new sediment continuity model would be used to compute large-scale aggradation or degradation of the river bed under the influence of grain size selective transport and vertical sorting. In this case study, however, net aggradation or degradation of the flume bed did not occur. This specific circumstance enables us to study in detail the relation between grain size-selective transport and vertical sorting. Another characteristic of this case study is that no submodel is required for the volume fraction content of size fractions in the transported sediment (fractional transport), as this parameter is computed by the model itself.

\subsection{Details of the Flume Experiments}

[57] Flume experiments B2 and A2 [Blom et al., 2003] were conducted in the Sand Flume of WL Delft Hydraulics. The length and width of the flume's measurement section were $50 \mathrm{~m}$ and $1.0 \mathrm{~m}$, respectively. The sediment mixture consisted of three well-sorted grain size fractions $\left(d_{1}=0.68 \mathrm{~mm}, d_{2}=2.1 \mathrm{~mm}\right.$, and $\left.d_{3}=5.7 \mathrm{~mm}\right)$.

[58] Experiment B2 started from the final stage of experiment B1. The initial bed of B2 consisted of a coarse bed layer on top of a substrate composed of only the fine size fraction. Small barchan-type bed forms were present on top of this coarse top layer (Figure 9a). Their mean bed form height $\bar{\Delta}$ and length $\bar{\lambda}$ were equal to $1.8 \mathrm{~cm}$ and $99 \mathrm{~cm}$, respectively. Right after the start of the experiment, the discharge was increased and the coarse layer was entrained. After this, the underlying fine sediment became available to the transport process and the bed form height quickly increased. The volume fraction of the fine size fraction in the transported material gradually increased, whereas the proportion of the medium and coarse fractions in the transported material slowly decreased, since they were gradually worked down to lower bed elevations. The coarse material in the lower parts of the bed forms did not constitute a distinct coarse bed layer over which the bed forms migrated, but participated in the transport process. The vertical sorting profile seemed to be primarily determined by grain size selective deposition down the avalanche lee face. In the equilibrium stage of experiment B2, the mean bed form height $\bar{\Delta}$ and length $\bar{\lambda}$ were equal to $12.2 \mathrm{~cm}$ and $1.79 \mathrm{~m}$, respectively.

[59] Experiment A2 started from the final stage of experiment A1. The initial bed of A2 consisted of a coarse bed layer on top of a substrate composed of a mixture of equal proportions of the three size fractions. Small barchan-type bed forms were present on top of this coarse top layer (Figure 9b). Their mean bed form height $\bar{\Delta}$ and length $\bar{\lambda}$ were equal to $1.7 \mathrm{~cm}$ and $90 \mathrm{~cm}$, respectively. Right after the start of the experiment, the discharge was increased to the same rate as in B2. The bed form height increased and the volume fraction of the coarse fraction in the transported material quickly increased. The lower elevations of the active bed showed a clear coarsening compared with the upper ones. The vertical sorting profile seemed to be determined by the grain size-selective deposition down the avalanche lee face, as well as by the winnowing of fines from the trough surface and subsurface, and partial transport. In the equilibrium stage of experiment $\mathrm{A} 2$, the mean bed form height $\bar{\Delta}$ and length $\bar{\lambda}$ were equal to $4.9 \mathrm{~cm}$ and

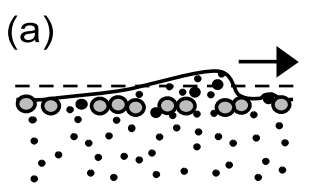

B1

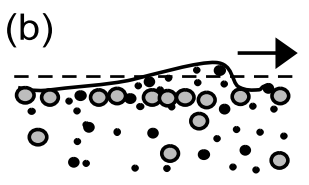

A1

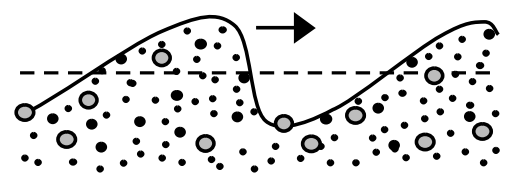

B2

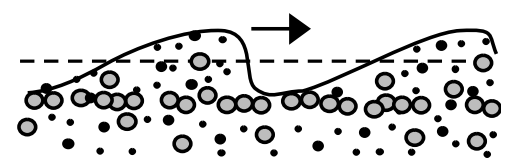

A2
Figure 9. Interpretation of initial and equilibrium stages of experiments (a) B2 and (b) A2 [Blom et al., 2003]. 
Table 2. Experimental Parameters, Averaged Over the Equilibrium Period ${ }^{\mathrm{a}}$

\begin{tabular}{|c|c|c|c|c|c|c|c|c|c|c|c|c|c|c|c|}
\hline Exp & $\bar{h} \mathrm{~m}$ & $\bar{u} \mathrm{~m} / \mathrm{s}$ & $\bar{F} r-$ & $\bar{i}_{E} 10^{-3}$ & $\bar{C} \mathrm{~m}^{1 / 2} / \mathrm{s}$ & $\bar{R} \mathrm{~m}$ & $\bar{\tau}_{b} \mathrm{~N} / \mathrm{m}^{2}$ & $\bar{\lambda} \mathrm{m}$ & $\bar{\Delta} \mathrm{cm}$ & $\bar{\Delta}_{b} \mathrm{~cm}$ & $\bar{c} \mathrm{~m} / \mathrm{h}$ & $\bar{q}_{a} \mathrm{~m}^{2} / \mathrm{s}$ & $\bar{F}_{a 1}-$ & $\bar{F}_{a 2}-$ & $\bar{F}_{a 3}-$ \\
\hline A2 & 0.320 & 0.83 & 0.47 & 1.8 & 38 & 0.271 & 4.6 & 1.38 & 4.9 & 2.9 & 8.8 & $4.3 \times 10^{-5}$ & 0.38 & 0.38 & 0.24 \\
\hline $\mathrm{B} 2$ & 0.389 & 0.69 & 0.35 & 2.2 & 25 & 0.351 & 7.4 & 1.79 & 12.2 & 7.3 & 3.7 & $4.5 \times 10^{-5}$ & 0.90 & 0.05 & 0.05 \\
\hline
\end{tabular}

${ }^{\mathrm{a}}$ From Blom et al. [2003]. Symbols denote water depth $(\bar{h})$, flow velocity $(\bar{u})$, Froude number $(\bar{F} r)$, energy slope $\left(\bar{i}_{E}\right)$, dimensional Chézy roughness coefficient $(\bar{C})$, hydraulic radius $(\bar{R})$, bed shear stress $\left(\bar{\tau}_{b}\right)$, bed form length $(\bar{\lambda})$, bed form height $(\bar{\lambda})$, relative trough elevation $\left(\bar{\Delta}_{b}\right)$, bed form migration speed $(\bar{c})$, volume of bed load transport per unit width and time $\left(\bar{q}_{a}\right)$, and volume fraction contents of the fine, medium, and coarse size fractions in the bed load transport $\left(\bar{F}_{a 1}, \bar{F}_{a 2}\right.$, and $\bar{F}_{a 3}$, respectively) averaged over the equilibrium periods. The overbar indicates that a parameter is averaged over a large number of bed forms. The Chézy roughness coefficient, hydraulic radius, and bed shear stress have been corrected for sidewall roughness, using the method of Vanoni and Brooks [1957].

$1.38 \mathrm{~m}$, respectively. Table 2 lists the main parameters which were averaged over the equilibrium period, i.e., the period in which all variables varied around steady mean values.

[60] Vertical sorting profiles were measured using a core sampling box [Blom et al., 2003]. The core samples were cut into thin layers which were sieved separately. In addition to the initial stage and the equilibrium stage ( $\mathrm{E}$ stage), samples were also taken once before equilibrium was reached (the nonequilibrium $\mathrm{N}$ stage) in order to study the time evolution of the sorting profile (see Figure 10). In each sampling session, about 15 core samples were taken. A remark needs to be made on the dispersive effects of the coring method, as it may cause relatively coarse grains located near the walls of the sampling box to be pushed down with it. No corrections were made for it. As a consequence, in the presented figures of the measured vertical sorting profiles the coarse grains may be found at elevations somewhat deeper than their real location. The maximum error in the measured volume fraction content of a certain size fraction at a certain elevation was found to be as large as \pm 0.2 , which is the deviation from a known fraction content in a newly installed bed configuration (stage B0). In this stage, the vertical sorting profile shows a very sharp unnatural transition at a certain elevation of the bed. For the more natural sorting profiles as considered in this paper, the potential error was estimated to be much smaller, about \pm 0.05 , especially because the sorting profile has been averaged over a number of core samples. The value \pm 0.05 is the deviation from a known fraction content in another newly installed bed configuration (stage A0), which is a more natural situation.

\subsection{Results}

[61] In this section we show the results of applying equations (27) and (43) to describe the time evolution of both the vertical sorting profile and the bed load transport composition in a situation without net aggradation or degradation. Note that the ratio between the mean bed form length, $\bar{\lambda}$, the mean bed form height, $\bar{\Delta}$, and the total bed load transport rate, $\bar{q}_{a}$, are assumed to be steady during the experiments. Their values have been set equal to their equilibrium values, which are given in Tables 2 and 3 of Blom et al. [2003]. The angle of repose of the lee faces is assumed to be equal to $30^{\circ}$. The initial sorting profiles of experiments B2 and A2 equal the measured initial sorting profiles (final stage of experiments B1 and A1, respectively).

[62] Figure 11 shows the computed time evolution of the vertical sorting profile, as well as the probability distribu- tion of bed surface elevations, $\bar{P}_{s}$, at the corresponding time. Equations (39) and (40) describe how $\bar{P}_{S}$ is derived from the measured time evolution of the PDF of relative trough elevations. Figure 11 illustrates how the computed sorting pattern of experiment B2 gradually develops toward its equilibrium profile and that the range of active bed elevations over which the sorting takes place increases. The coarse particles settle primarily to the lower lee face elevations and the finer particles to the upper lee face elevations. Figure 11 illustrates that at the lower elevations of the active part of the bed the grain size distribution adapts more slowly than at the upper ones.

[63] Note that the inflection point of the vertical sorting profile is always located at the mean bed level. This is due to the way of modeling grain size-selective deposition down a lee face in combination with the way of modeling the irregularity of bed forms. Individual stoss and lee faces are assumed to be asymmetric around the mean bed level.

[64] In Figure 12, the computed sorting profiles are compared to the measured ones, for the nonequilibrium stage and the equilibrium stage of experiment B2, stages $\mathrm{B} 2 \mathrm{~N}$ and $\mathrm{B} 2 \mathrm{E}$, respectively. The measured sorting profile of phase B2E shows a top layer coarser than the material underneath. This seems to be due to (1) the formation of a thin mobile armor layer over the stoss face and (2) deposition of sediment that was being transported until the flow was turned off. The computed sorting profiles do not show such a coarse top layer, since in the sorting evolution model it is assumed that the composition of the net entrainment flux on the stoss face has the same composition as the bed material at that elevation.

[65] The computed sorting profile for the nonequilibrium stage $(\mathrm{B} 2 \mathrm{~N})$ shows reasonable agreement with the data, as the computed volume fraction contents of the size fractions have the right order of magnitude. The computed sorting profile for the equilibrium stage B2E agrees well with the

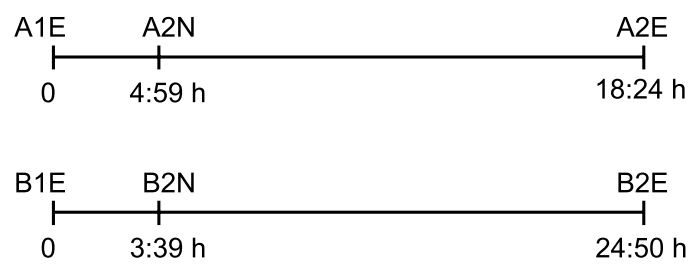

Figure 10. Times (in flow hours) of the core sampling sessions in flume experiments $\mathrm{A} 2$ and $\mathrm{B} 2$ [Blom et al., 2003]. 

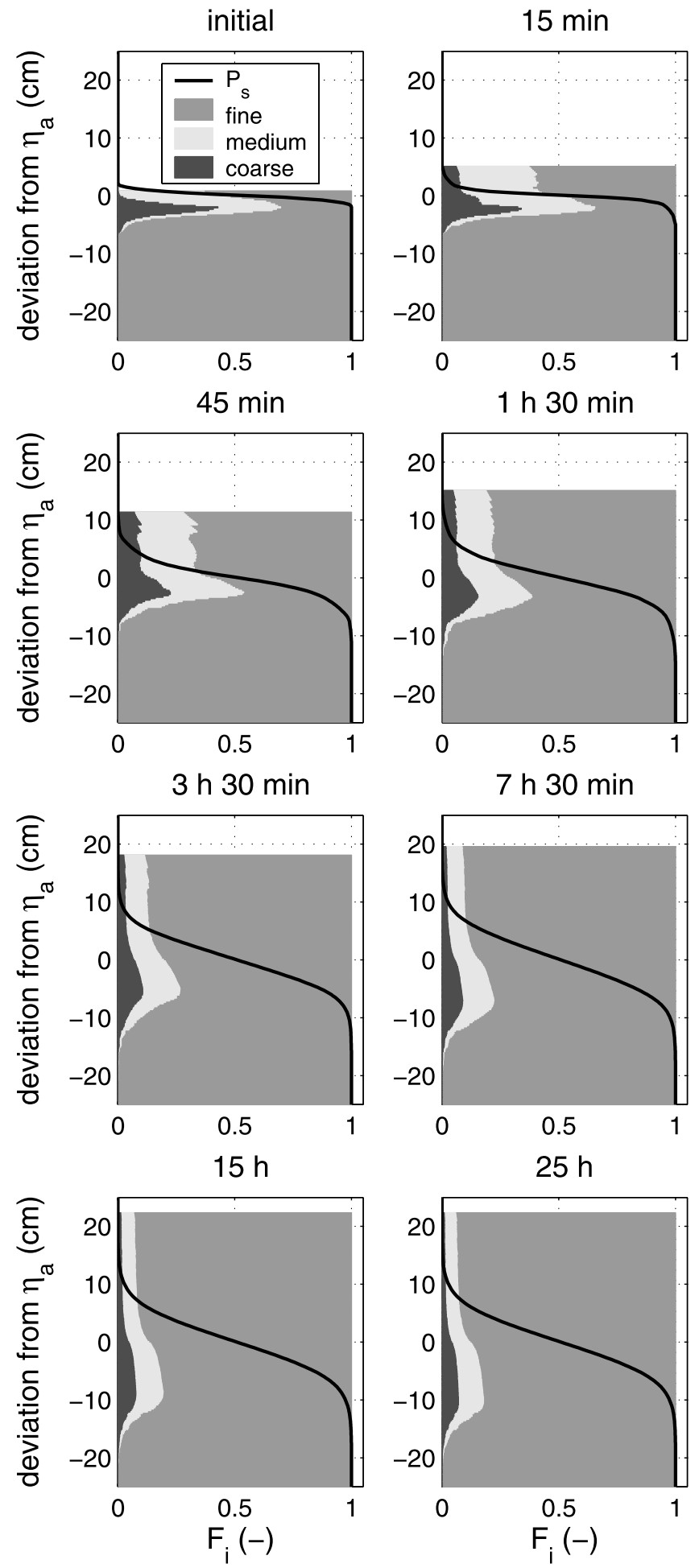

Figure 11. The computed time evolution of the sorting profile, $\bar{F}_{i}$, for experiment B2. The solid line represents the probability distribution of bed surface elevations, $\bar{P}_{s}$, in the corresponding phase of the experiment. (top left) The measured vertical sorting profile at the initial stage of experiment B2. measured one, considering the large variation in the sorting profiles from different core samples.

[66] Note that the measured range of bed elevations is small compared to the range of elevations covered by the computations (Figure 12). The measured range of bed elevations shows the range covered by the core samples, while the computed range is the range of active bed elevations. The latter is based on the PDF of measured trough elevations, as well as on the assumption that each bed form crest is located at the same vertical distance from the mean bed level as its trough. In reality, however, the deepest bed form troughs are usually not accompanied by the highest crests [Leclair and Blom, 2005]. This causes the computed range of active bed elevations to be larger than the measured one. Yet, since the probability density of these upper elevations being exposed to the flow, $\bar{p}_{e}$, is very small, these elevations have negligible influence on, for
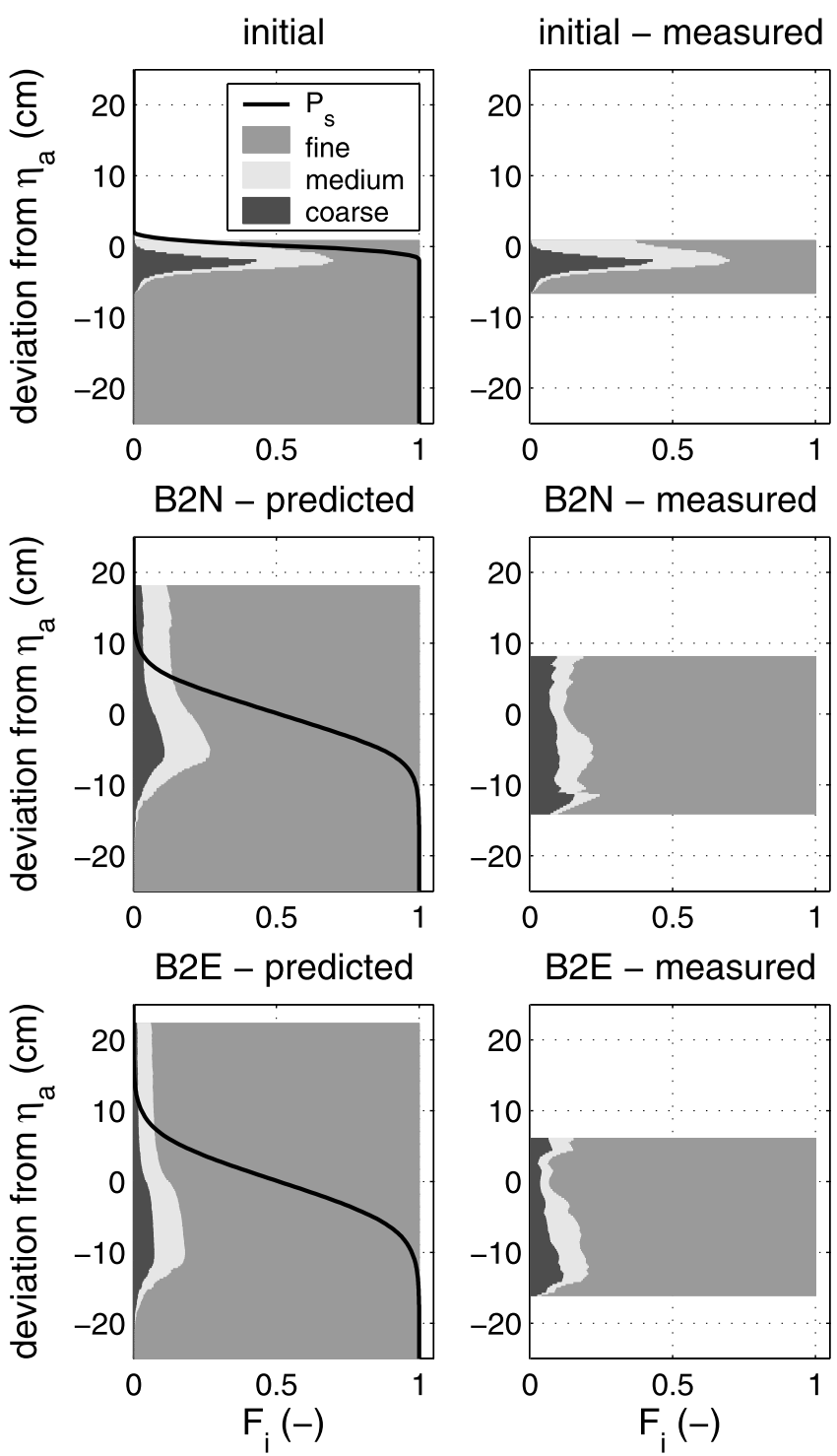

B2E - measured

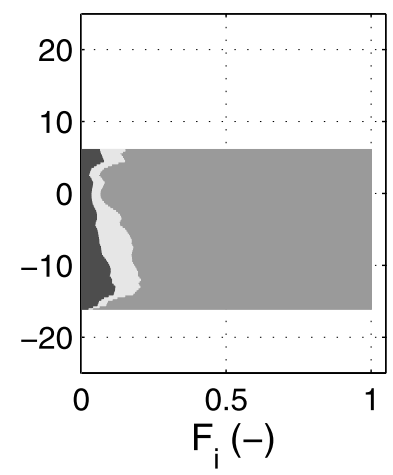

Figure 12. Comparison of the measured and computed sorting profiles, $\vec{F}_{i}$, for the nonequilibrium stage and the equilibrium stage of experiment B2. (top left) The measured vertical sorting profile at the initial stage of experiment B2. 


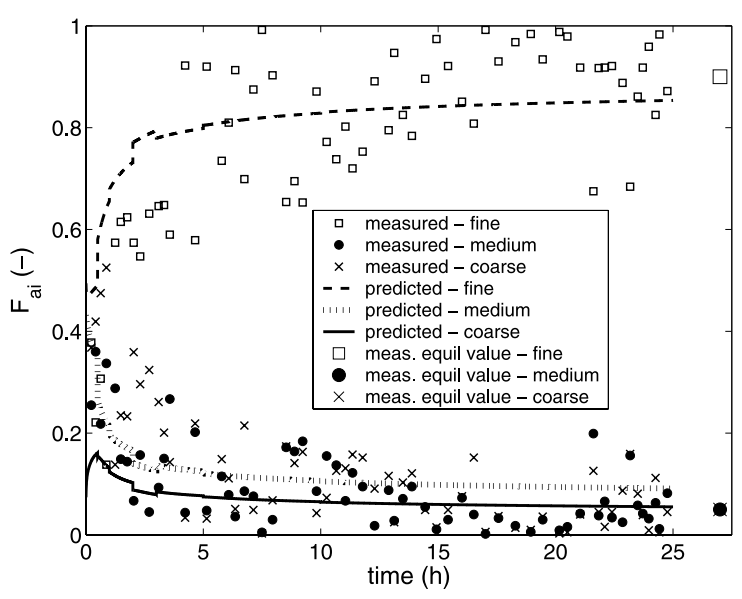

Figure 13. Measured and computed time evolution of the volume fraction content of size fractions in the bed load transport, $\bar{F}_{a i}$, for experiment B2. Note that the large markers on the right-hand side of the plot represent the measured composition of the bed load transport averaged over the equilibrium period.

instance, the composition of the sediment transported over the crests. More important to the sorting evolution calculations than these upper elevations are the lower elevations of the active bed. Unfortunately, these lower elevations are not entirely covered by the core samples.

[67] Figure 13 shows the measured and computed time evolution of the mean composition of the bed load transport for experiment B2. The agreement between the measured and computed time evolution of the mean transport composition is reasonably good, which implies that the physical mechanisms are simulated rather well by the model. The computed values are close to the measured composition of the sediment transport averaged over the equilibrium period. Note that the discontinuities in the computed composition are not due to numerical problems, but to the imposed transitions in the time evolution of the PDF of relative trough elevations (see Figure 7).

[68] Figure 14 considers flume experiment A2. The initial sorting profile of the experiment was the final stage of experiment A1 (stage A1E), in which small bed forms migrated over a coarse bed layer. During the experiment, the downward coarsening trend remains, but covers an increasing range of bed elevations. Comparing the computed sorting profiles with the measured ones, we can see that the formation of a coarse bed layer in the lower parts of migrating bed forms (between 3 and $5 \mathrm{~cm}$ below the mean bed level) is not adequately described by the model. The disagreement between the computed and measured sorting profiles is larger for A2 than for B2, which appears to be due to the model's inadequate description of the formation of a coarse bed layer. In the sorting evolution model, the dominant sorting mechanism is the grain size-selective deposition down a bed form lee face. The present version of the model does not account for the mechanisms of (1) the winnowing of fines from the trough surface and subsurface and (2) the settling of immobile coarse grains, whereas these mechanisms play a significant role in the formation of a coarse bed layer.

[69] Figure 15 illustrates that the computed time evolution of the mean composition of the sediment transport lies within the scatter of the measured data. The computed values are fairly close to the measured composition of the sediment transport averaged over the equilibrium period.

\subsection{Approach to Equilibrium}

[70] For both experiments B2 and A2, calculations have been continued until 500 flow hours. Figure 16 shows the computed time evolution of the bed load transport composition. Figure 16 illustrates that, at the end of the experiments (B2 at 25 flow hours, A2 at 18 flow hours), the computed bed load transport composition is already close to its equilibrium composition. This also applies to the sorting
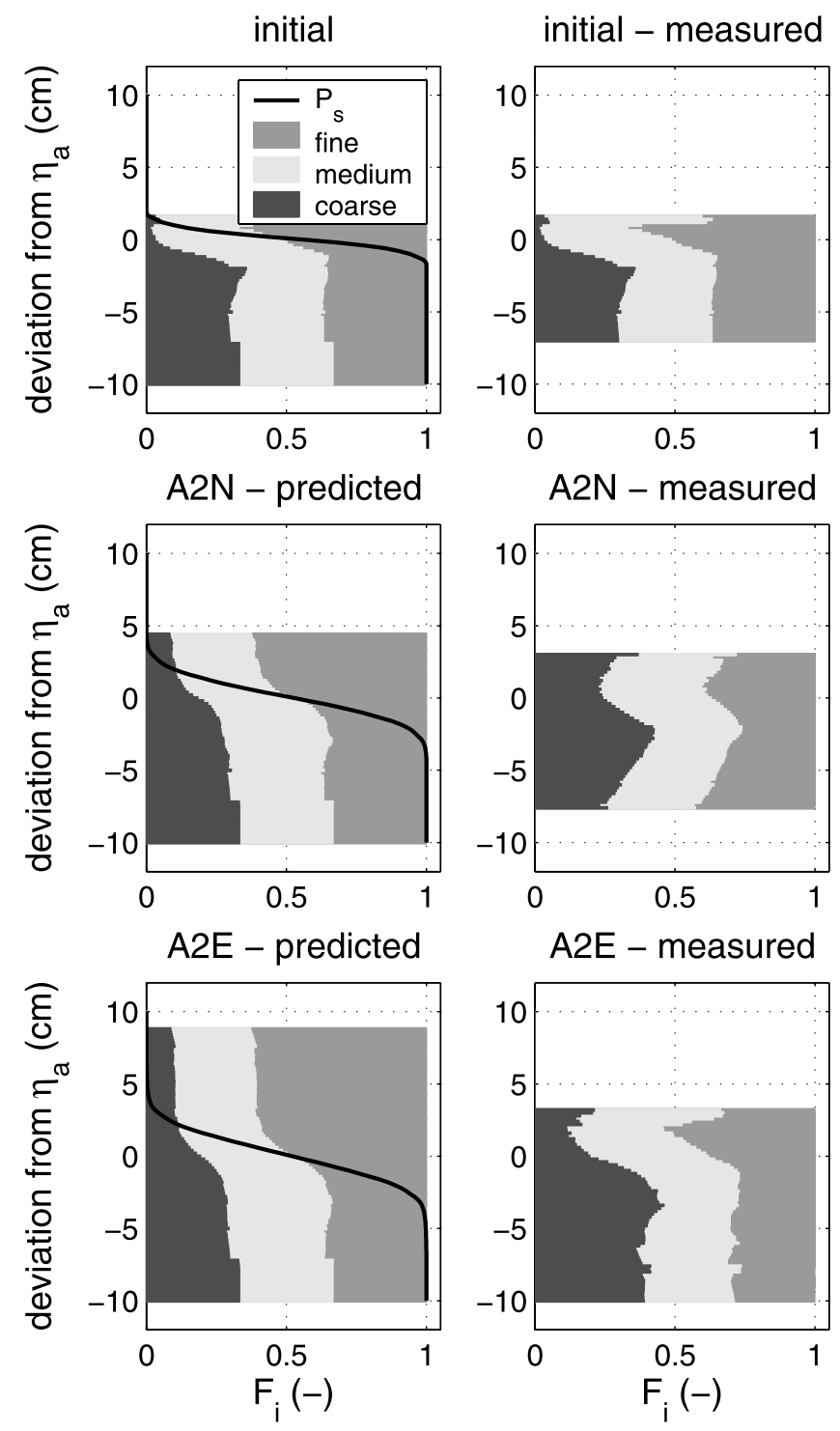

Figure 14. Comparison of the measured and computed sorting profiles, $\bar{F}_{i}$, for the nonequilibrium stage and the equilibrium stage of experiment A2. (top left) The measured vertical sorting profile at the initial stage of experiment A2. 


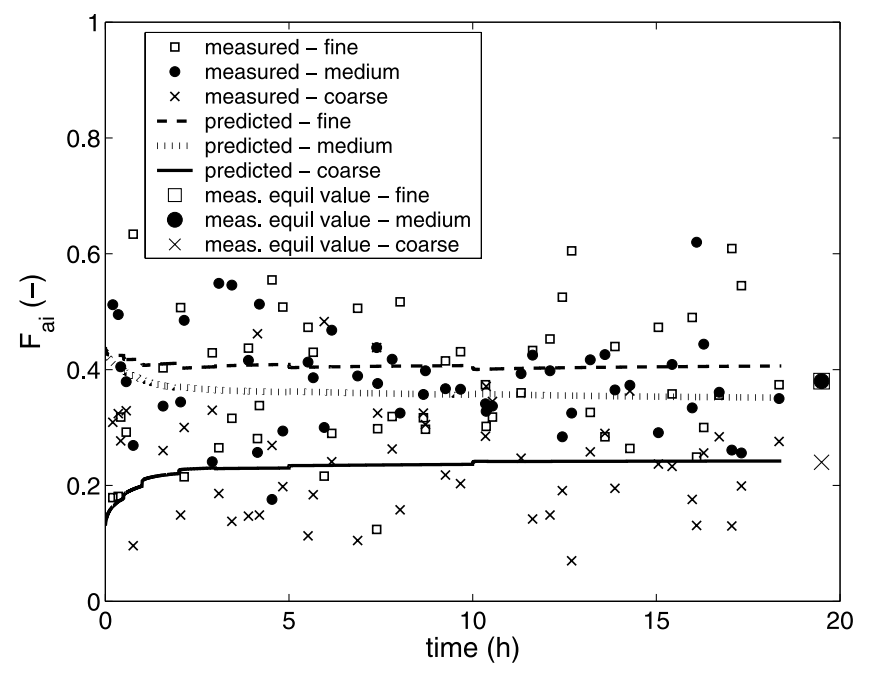

Figure 15. Measured and computed time evolution of the volume fraction content of size fractions in the bed load transport, $\bar{F}_{a i}$, for experiment A2. Note that the large markers on the right-hand side of the plot represent the measured composition of the bed load transport averaged over the equilibrium period.

profiles (Figure 17). Between the end of the experiment and 500 flow hours, mainly the very low elevations of the active bed continue adapting toward their equilibrium compositions. This slow adaptation, which reflects the infrequency of deep scour, influences the composition of the bed load transport only slightly (Figure 16).

\subsection{Comparison of Timescales}

[71] For experiments B2 and A2, Figure 18 shows the timescale of the adaptation of sorting, $T_{f}$, according to equation (52), together with the timescale of dune migration, $T_{c}$, according to equation (50). In the lower parts of the active bed, the timescale of sorting, $T_{f}$, appears to be much larger than the timescale of dune migration, whereas in the upper parts the timescale of sorting is smaller than the one of dune migration. One of the constraints of the sorting evolution model is, however, that the timescale of migration must be smaller than the timescale of sorting. This constraint arises from the assumption that the sediment deposited at elevation $z$ is immediately mixed with all sediment present at this elevation. This implies that the time evolution
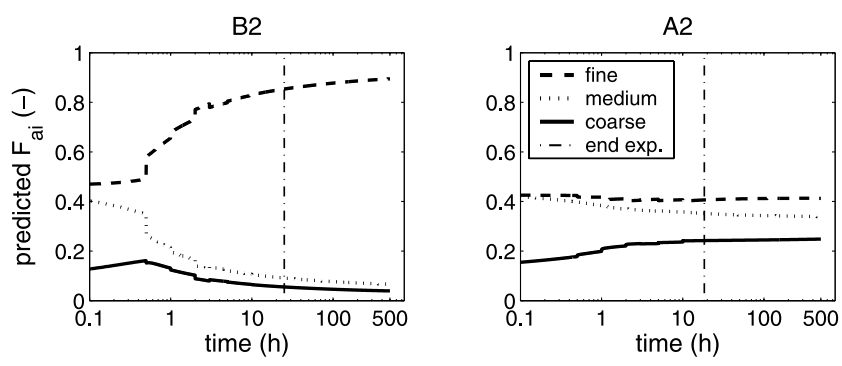

Figure 16. The computed composition of the bed load transport until 500 flow hours, for experiments (a) B2 and (b) A2. Note the log scale on the $\mathrm{x}$ axis. of the sorting in the upper parts of the active bed may not be adequately described by the model.

\section{Discussion and Conclusions}

[72] We have developed a new sediment continuity model that accounts for the time evolution of grain size-selective transport and the vertical sorting profile in the computation of large-scale morphodynamic changes (i.e., net degradation or aggradation) of the river bed. The resulting sediment continuity model is called the sorting evolution model. The model is based on a stochastic description of the bed elevations interacting with the flow rather than on the commonly used discrete representation of these elevations. The sorting evolution model is a relaxation-type model allowing specification of an appropriate timescale of sorting.

[73] The presented model has been derived for rivers wherein the bed is fully covered by bed forms and where the bed forms are characterized by a lee face (ripples or dunes). Hassan and Church [1994] remark how in such rivers the reworking or redistribution of sediment is dominated by the migrating bed forms, whereas in gravel bed rivers with an armor layer under lower regime plane bed conditions, the reworking is more sporadic and primarily results from local scour and fill. This has been confirmed in flume experiments conducted by Wong Egoavil [2006]. While the present research is aimed at conditions dominated by river dunes, we refer to the work by Wong Egoavil [2006] for a probabilistic formulation of sediment continuity under plane bed conditions.

[74] The following data is required as input to the model: the initial sorting profile; the time evolution of the PDF of
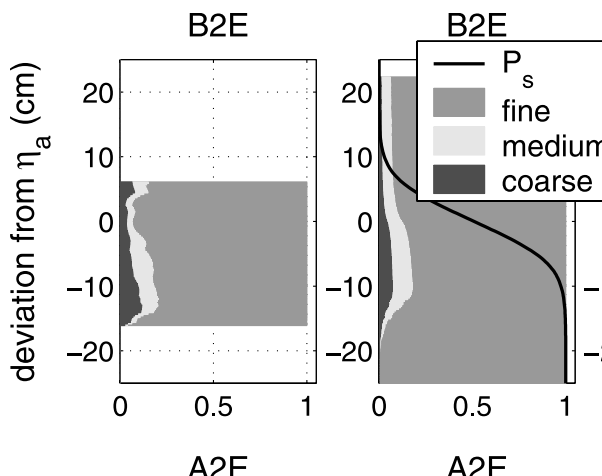

B2 - $500 h$
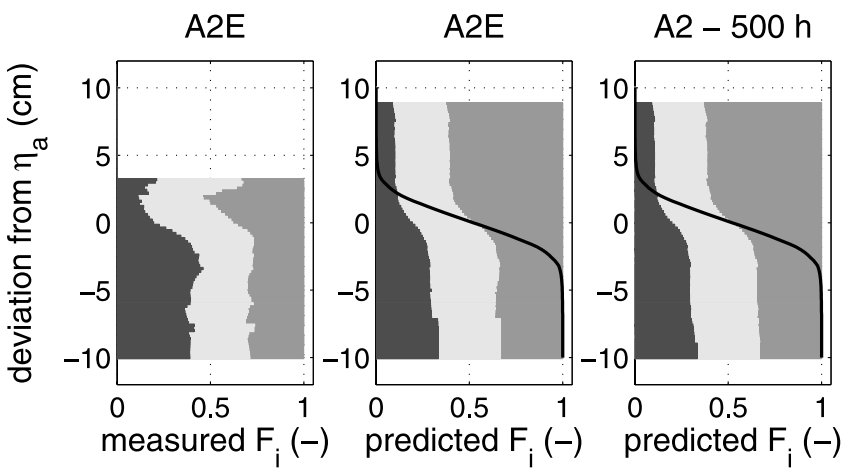

Figure 17. The measured sorting profile at the end of the experiment, the computed sorting profile at the end of the experiment, and the computed sorting profile after 500 flow hours for experiments B2 and A2. 

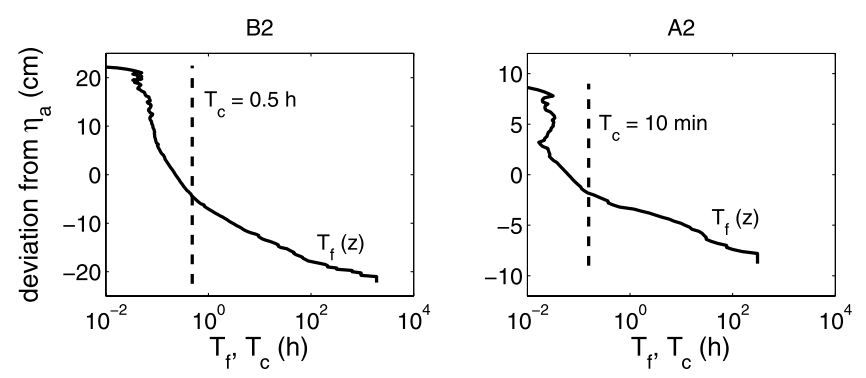

Figure 18. Timescale of vertical sorting, $T_{f}(z)$, according to equation (52), and the timescale of dune migration, $T_{c}$, according to equation (50), for experiments $\mathrm{B} 2$ and A2. Note the log scale on the $\mathrm{x}$ axis.

relative trough elevations or the probability distribution of bed surface elevations; the time evolution of the total bed load transport rate; and the time evolution of the ratio of the mean dune length to the mean dune height. The model generates as output the time evolution of the net aggradation or degradation of the river bed, as well as the volume fraction content of size fractions in the bed load transport. In the present analysis we have used the measured (time evolution of the) PDF of relative trough elevations as input to the computations. In predictive calculations such measured data is not available, and in these cases we need to predict the time evolution of the PDF of relative trough elevations or the probability distribution of bed elevations using an external submodel. A relatively simple version of such a submodel has been proposed by Van der Mark et al. [2005].

[75] The sorting evolution model has been verified by comparing the computed time evolution of both the sorting profile and volume fraction content of size fractions in the bed load transport with measured data from experiments B2 and A2. After the calibration of the lee sorting function on the equilibrium stages of the same flume experiments $[$ Blom et al., 2006], no additional parameters in the sorting evolution model have been calibrated to force agreement with data. The computational results agree reasonably well with the data. Nevertheless, the formation of a coarse bed layer in the lower parts of migrating bed forms is not adequately described by the model. It is emphasized that the sorting evolution model's main sorting mechanism is the grain size-selective deposition over the lee face. The model does not allow for grain size-selective entrainment over the stoss face, as all particles present at a certain elevation of the active bed are assumed to be transported over the bed form crest. This implies that particles that are present on the stoss face and too coarse to be transported are not allowed to settle down as the bed form migrates. Also the winnowing of fines from the trough surface and subsurface is not included in the model. The mechanisms of winnowing of fines and the settling of immobile coarse particles need to be incorporated in a later version of the model, so as to improve the description of the formation of a coarse bed layer.

[76] The new sorting evolution model serves as a basis to the authors for a future simplification of the model into a new stochastics-based bed layer type sediment continuity model in which vertical sediment fluxes are included in a parameterized way. Further research is required into the following topics: the incorporation of suspended load transport in the morphodynamic model system for nonuniform sediment; the derivation of a model for skin friction based on the mean composition of the bed surface; and the derivation of a model for form drag based on the PDF of bed surface elevations. Note that application of the sorting evolution model in the present study is limited to conditions that vary in vertical direction only. Blom [2008] applies the sorting evolution model to conditions that vary also in streamwise direction, i.e., an aggradational flume experiment.

\section{Appendix A: Lee Sorting Function}

[77] The lee sorting function, $\omega_{i}$, describes to what extent a specific size fraction that is transported over the bed form crest is deposited at a certain elevation of the lee face, and is given by Blom and Parker [2004]:

$$
\omega_{i}=J\left(1+\delta_{i} z^{*}\right)
$$

where $\delta_{i}$ is the lee sorting parameter, which is considered below, an asterisk denotes a parameter is dimensionless, and $z^{*}$ denotes the dimensionless vertical coordinate relative to the mean bed level $\bar{\eta}_{a}$. For triangular dunes $z^{*}=\left(z-\bar{\eta}_{a}\right) / \Delta$, where $\Delta$ denotes bed form height. The Heaviside step function $J$ equals 1 if elevation $\mathrm{z}$ is covered by the bed form. $J$ equals 0 if elevation $z$ is outside the range of elevations covered by the specific bed form:

$$
J=\left\{\begin{array}{cc}
1 & \text { if } \eta_{b} \leq z \leq \eta_{t} \\
0 & \text { else }
\end{array}\right.
$$

where $\eta_{t}$ denotes the crest elevation of the specific bed form. [78] As a first step toward a generic formulation, Blom et al. [2006] derive the following expression for the lee sorting parameter, $\delta_{i}$ :

$$
\delta_{i}=0.3 \frac{\phi_{i}-\bar{\phi}_{m t o p}}{\bar{\sigma}_{a}}\left(\bar{\tau}_{b}^{*}\right)^{-0.5}
$$

Although the calibration was done for steady conditions, we assume the two constants in this equation to be generally valid. In equation (A3), $\bar{\tau}_{b}{ }^{*}$ denotes the overall dimensionless bed shear stress, $\bar{\sigma}_{a}$ denotes the overall arithmetic standard deviation of the lee deposit, and $\bar{\phi}_{m t o p}$ denotes the overall arithmetic mean grain size of the lee deposit. The overbar indicates that a parameter is averaged over some horizontal distance, e.g., a large number of bed forms, which is indicated by the term overall. $\phi_{i}$ denotes the arithmetic grain size of size fraction $i$ :

$$
\phi_{i}=-\log _{2}\left(d_{i} / d_{r e f}\right)
$$

where $d_{i}$ denotes the grain size of size fraction $i$ and in which the geometric reference grain size, $d_{r e f}$, equals $1 \mathrm{~mm}$. Note that equation (A4), with $d_{r e f}=1 \mathrm{~mm}$, equals the conventional manner in which the arithmetic mean grain size is calculated. Yet, equation (A4) is the mathematically correct notation, as logarithms cannot be taken of nondimensionless parameters. As a result, the arithmetic 
grain size $(\phi)$ is correctly dimensionless. In equation (A3), the overall arithmetic mean grain size of the lee deposit, $\bar{\phi}_{m t o p}$, is given by

$$
\bar{\phi}_{\text {mtop }}=\sum_{i}^{N} \phi_{i} \bar{F}_{\text {topi }}
$$

The overall arithmetic standard deviation of the lee deposit, $\bar{\sigma}_{a}$, is given by

$$
\bar{\sigma}_{a}^{2}=\sum_{i}^{N}\left(\phi_{i}-\bar{\phi}_{m t o p}\right)^{2} \bar{F}_{t o p i}
$$

and the overall dimensionless bed shear stress, $\bar{\tau}_{b}{ }^{*}$, is defined as

$$
\bar{\tau}_{b}^{*}=\bar{\tau}_{b} /\left[\left(\rho_{s}-\rho\right) g \bar{d}_{m t o p}\right]
$$

where $\rho_{s}$ and $\rho$ denote the density of sediment and water, respectively, $g$ denotes the gravitational acceleration, $\bar{\tau}_{b}$ denotes the bed shear stress averaged over a series of bed forms (defined as $\bar{\tau}_{b}=\rho g \bar{R} \bar{i}_{E}$ where $\bar{R}$ denotes the overall hydraulic radius and $\bar{i}_{E}$ denotes the overall energy slope), and

$$
\bar{d}_{m t o p}=d_{r e f} 2^{-\bar{\phi}_{m t o p}}
$$

where $\bar{d}_{\text {mtop }}$ denotes the overall geometric mean grain size of the lee deposit.

\section{Notation}

$\bar{c}$ bed form migration speed averaged over a series of bed forms, $\mathrm{m} \mathrm{s}^{-1}$.

$c_{b}$ sediment concentration within the bed $\left(c_{b}=1-\right.$ $\left.\lambda_{b}\right)$.

$\bar{C}$ dimensional Chézy roughness coefficient averaged over a series of bed forms, $\mathrm{m}^{1 / 2} \mathrm{~s}^{-1}$.

$\bar{C}_{i}$ concentration of size fraction $i$ at elevation $z$, averaged over a series of bed forms.

$d_{90}$ geometric grain size for which $90 \%$ of the sediment mixture is finer, $\mathrm{m}$.

$d_{i}$ geometric grain size of size fraction $i, \mathrm{~m}$.

$\bar{d}_{\text {mtop }}$ geometric mean grain size of the lee deposit, averaged over a series of bed forms, $\mathrm{m}$.

$d_{\text {ref }}$ geometric reference grain size $\left(d_{\text {ref }}=1 \mathrm{~mm}\right)$.

$\bar{D}$ volume of deposited sediment per unit area and time, summed over all size fractions and averaged over a series of bed forms, $\mathrm{m} \mathrm{s}^{-1}$.

$\bar{D}_{e} \quad$ deposition density defined like $\bar{D}_{e i}$ but summed over all size fractions, $\mathrm{s}^{-1}$.

$\bar{D}_{e i}$ deposition density of size fraction $i$ defined such that $\bar{D}_{e i} d x d z$ is the volume of sediment of size fraction $i$ that is deposited in a bed element with sides $d x$ and $d z$ at elevation $z$, per unit width and time, averaged over a series of bed forms, $\mathrm{s}^{-1}$.

$D_{l}$ volume of sediment deposited onto the lee face per unit area and time (i.e., deposition rate at the lee face), $\mathrm{m} \mathrm{s}^{-1}$.
$D_{s i} \quad$ volume of sediment of size fraction $i$ locally deposited onto the stoss face, per unit area and time, $\mathrm{m} \mathrm{s}^{-1}$.

$\bar{E} \quad$ volume of entrained sediment per unit area and time, summed over all size fractions and averaged over a series of bed forms, $\mathrm{m} \mathrm{s}^{-1}$.

$\bar{E}_{e}$ entrainment density defined like $\bar{E}_{e i}$ but summed over all size fractions, $\mathrm{s}^{-1}$.

$\bar{E}_{e i}$ entrainment density of size fraction $i$, defined such that $\bar{E}_{e i} d x d z$ is the volume of sediment of size fraction $i$ that is entrained from a bed element with sides $d x$ and $d z$ at elevation $z$, per unit width and time, averaged over a series of bed forms, $\mathrm{s}^{-1}$.

$E_{\text {snet }}$ net entrained volume of all size fractions on the stoss face, per unit area and time, $\mathrm{m} \mathrm{s}^{-1}$.

$\hat{E}_{\text {snet }}$ net entrained volume of all size fractions on the stoss face at elevation $z$, per unit area and time, averaged over a series of bed forms, $\mathrm{m} \mathrm{s}^{-1}$.

$\bar{E}_{\text {snet }}$ net entrained volume of all size fractions on the stoss face, per unit area and time, averaged over a series of bed forms, $\mathrm{m} \mathrm{s}^{-1}$.

$E_{s i}$ volume of sediment of size fraction $i$ locally entrained from the stoss face, per unit area and time, $\mathrm{m} \mathrm{s}^{-1}$.

$E_{\text {siu }}$ volume of sediment of size fraction $i$ locally entrained from the stoss face, per unit area and time, if only sediment of size fraction $i$ would be present, although hiding exposure effects may be included, $\mathrm{m} \mathrm{s}^{-1}$.

$f_{\text {susp }}$ grain size-selective model for suspended load transport of nonuniform sediment.

$\bar{F}_{a i} \quad$ volume fraction content of size fraction $i$ in the bed load transport, averaged over a series of bed forms (i.e., the bed load transport composition).

$\bar{F}_{i} \quad$ volume fraction content of size fraction $i$ in the bed at elevation $z$, averaged over a series of bed forms.

$F_{\text {leeloci }}$ volume fraction content of size fraction $i$ in the sediment deposited at elevation $z$ at the lee face.

$F_{m i}$ volume fraction content of size fraction $i$ in the active layer.

$\bar{F}_{P i}$ volume fraction content of size fraction $i$ in the total amount of sediment entrained from the bed due to a change in time of the PDF of relative trough elevations, averaged over a series of bed forms.

$\bar{F}_{q s i} \quad$ volume fraction content of size fraction $i$ in the bed load transport at the stoss face at elevation $z$, averaged over a series of bed forms.

$\bar{F} r \quad$ Froude number.

$\bar{F}_{\text {suri }}$ volume fraction content of size fraction $i$ at the bed surface, averaged over a series of bed forms (i.e., mean bed surface composition).

$\bar{F}_{\text {topi }}$ volume fraction content of size fraction $i$ in the bed load transport at the bed form crest, averaged over a series of bed forms.

$g$ gravitational acceleration, $\mathrm{m} \mathrm{s}^{-2}$.

$h$ water depth averaged over a series of bed forms, $\mathrm{m}$.

$\bar{i}_{E}$ energy slope averaged over a series of bed forms. 
$I$ Heaviside step function which equals 1 if at elevation $\mathrm{z}$ sediment has been entrained, and as such the amount of sediment at elevation $\mathrm{z}$ has decreased (represented by $\left.\bar{P}_{s}\left(t_{2}\right) \leq \bar{P}_{s}\left(t_{1}\right)\right)$. Otherwise $I$ equals 0 .

$J$ Heaviside step function which equals 1 if elevation $\mathrm{z}$ is covered by the bed form. $J$ equals 0 if elevation $z$ is outside the range of elevations covered by the specific bed form.

$N$ total number of size fractions.

$\tilde{p}_{b}$ adapted probability density function of trough elevations relative to the mean bed level for a series of bed forms, indicating the probability density that the trough elevation equals $z$, weighted by the horizontal distance involved (i.e., PDF of relative trough elevations), $\mathrm{m}^{-1}$.

$\bar{p}_{e}$ probability density function of bed surface elevations for a series of bed forms, indicating the probability density that the bed surface elevation equals $z$ or the likelihood of elevation $z$ being exposed to the flow, $\mathrm{m}^{-1}$.

$p_{e}$ probability density function of bed surface elevations for an individual bed form, $\mathrm{m}^{-1}$.

$\tilde{p}_{\eta_{b}} \quad$ probability density function of trough elevations relative to the mean bed level for a series of bed forms, indicating the probability density that the trough elevation equals $z, \mathrm{~m}^{-1}$.

$\bar{P}_{s} \quad$ probability distribution of bed surface elevations for a series of bed forms, indicating the probability the bed surface elevation is higher than $z$.

$\tilde{P}_{s}$ probability distribution of bed surface elevations for a series of bed forms relative to the mean bed level, $\bar{\eta}_{a}$.

$\bar{q}_{a} \quad$ volume of bed load transport per unit width and time, averaged over a series of bed forms (excluding pores), $\mathrm{m}^{2} \mathrm{~s}^{-1}$.

$\bar{q}_{\text {top }}$ volume of bed load transport at the bed form crest per unit width and time, averaged over a series of bed forms (excluding pores), $\mathrm{m}^{2} \mathrm{~s}^{-1}$.

$\bar{q}_{\text {susp }}$ volume of suspended load transport per unit width and time, averaged over a series of bed forms, $\mathrm{m}^{2} \mathrm{~s}^{-1}$.

$\bar{R}$ hydraulic radius averaged over a series of bed forms, $\mathrm{m}$.

$t$ time coordinate, $\mathrm{s}$.

$T_{c}$ timescale of dune migration, i.e., the time required for a bed form to migrate over its mean bed form length $\bar{\lambda}$, s.

$T_{p}$ timescale of adaptation of dune dimensions, $\mathrm{s}$.

$T_{f}$ timescale of vertical sorting, s.

$T_{m}$ timescale of large-scale morphodynamic changes, $\mathrm{s}$.

$\bar{u}$ flow velocity averaged over a series of bed forms, $\mathrm{m} \mathrm{s}^{-1}$.

$x$ horizontal coordinate on a spatial scale of a large series of bed forms, $\mathrm{m}$.

$z$ vertical coordinate, $\mathrm{m}$.

$\tilde{z}$ vertical coordinate relative to the mean bed level $\bar{\eta}_{a}, \mathrm{~m}$.

$z^{*}$ vertical coordinate relative to the mean bed level $\bar{\eta}_{a}$, dimensionless.

$\alpha$ step length, dimensionless. $\delta$ thickness of the active layer, $\mathrm{m}$.

$\delta_{i} \quad$ lee sorting parameter.

$\Delta$ bed form height, $\mathrm{m}$.

$\bar{\Delta}$ bed form height averaged over a series of bed forms (i.e., mean bed form height), $\mathrm{m}$.

$\Delta_{b}$ vertical distance between the mean bed level and the trough (i.e., relative trough elevation), $\mathrm{m}$.

$\bar{\Delta}_{b}$ vertical distance between the mean bed level and the trough averaged over a series of bed forms (i.e., mean relative trough elevation), $\mathrm{m}$.

$\eta_{I}$ elevation of the interface between the active layer and the substrate $\left(\eta_{I}=\bar{\eta}_{a}-\delta\right), \mathrm{m}$.

$\bar{\eta}_{a}$ bed surface elevation averaged over a series of bed forms (i.e., mean bed level), m.

$\eta_{b}$ bed form trough elevation, $\mathrm{m}$.

$\eta_{\text {bmax }}$ highest bed form trough elevation, $\mathrm{m}$.

$\eta_{b m i n}$ lowest bed form trough elevation, $\mathrm{m}$.

$\eta_{t}$ bed form crest elevation, $\mathrm{m}$.

$\eta_{m n}$ lower limit of the active part of the bed, $\mathrm{m}$.

$\eta_{m x}$ upper limit of the active part of the bed, $\mathrm{m}$.

$\eta_{\text {stepi }}$ step length in $\mathrm{z}$ direction at elevation $z$ on the stoss face for size fraction $i, \mathrm{~m}$.

$\lambda$ bed form length, $\mathrm{m}$.

$\bar{\lambda}$ bed form length averaged over a series of bed forms (i.e., mean bed form length), $\mathrm{m}$.

$\lambda_{b}$ porosity.

$\lambda_{l}$ horizontal length of the bed form lee face, $\mathrm{m}$.

$\lambda_{s}$ horizontal length of the bed form stoss face, $m$.

$\Lambda_{i} \quad$ Einstein step length of size fraction $i, \mathrm{~m}$.

$\mu_{\Delta_{b}}$ mean value of relative trough elevation, $\mathrm{m}$.

$v$ angle of repose, ${ }^{\circ}$.

$\rho$ density of water, $\mathrm{kg} \mathrm{m}^{-3}$.

$\rho_{s}$ density of sediment, $\mathrm{kg} \mathrm{m}^{-3}$.

$\bar{\sigma}_{a}$ arithmetic standard deviation of the lee deposit, averaged over a series of bed forms.

$\sigma_{\Delta_{h}}$ standard deviation of relative trough elevation, $\mathrm{m}$.

$\bar{\tau}_{b}$ bed shear stress averaged over a series of bed forms, $\mathrm{N} \mathrm{m}^{-2}$.

$\bar{\tau}_{b}{ }^{*}$ bed shear stress averaged over a series of bed forms, dimensionless.

$\phi_{i}$ arithmetic grain size of size fraction $i$.

$\bar{\phi}_{\text {mtop }} \quad$ arithmetic grain size of the lee deposit, averaged over a series of bed forms.

$\omega_{i} \quad$ lee sorting function, specifying to what extent a specific size fraction that is transported over the bed form crest is deposited at elevation $z$ of the lee face.

Subscripts

$i$ number of the size fraction.

$l$ lee face.

$s$ stoss face.

$u$ case that only sediment of size fraction $i$ would be present, although hiding exposure effects may be included.

An asterisk denotes a parameter is dimensionless. An overbar indicates that a parameter is averaged over some horizontal distance, e.g., a large number of bed forms, which is indicated by the term overall. A tilde indicates a parameter is relative to the mean bed level. 
[79] Acknowledgments. The first author worked on the project in the pursuit of a doctoral degree at the Department of Civil Engineering of the University of Twente. The study was supported by the Institute for Inland Water Management and Waste Water Treatment (Rijkswaterstaat RIZA) of the Ministry of Transport, Public Works, and Water Management in the Netherlands, by WL Delft Hydraulics, and by the University of Twente. This paper is a contribution of the U. S. National Center for Earth-surface Dynamics (NCED), a National Science Foundation Science and Technology Center (Agreement EAR-0120914). More specifically, this paper addresses NCED's research efforts on channels and stream restoration. Netherlands Organization for Scientific Research (NWO) and the Prince Bernhard Cultural Foundation are acknowledged for their financial support for a 3 month stay by the first author at the St. Anthony Falls Laboratory. Huib J. de Vriend is gratefully acknowledged for his scientific support during the project. We thank Pieter C. Roos for bringing to our attention the mathematically correct formulation for the arithmetic grain size (equation (A4)).

\section{References}

Bagnold, R. A. (1941), The Physics of Blown Sand and Desert Dunes, Methuen, New York.

Blom, A. (2008), Different approaches to handling vertical and streamwise sorting in modeling river morphodynamics, Water Resour. Res., doi:10.1029/2006WR005474, in press.

Blom, A., and G. Parker (2004), Vertical sorting and the morphodynamics of bedform-dominated rivers: A modeling framework, J. Geophys. Res., 109, F02007, doi:10.1029/2003JF000069.

Blom, A., J. S. Ribberink, and H. J. de Vriend (2003), Vertical sorting in bed forms: Flume experiments with a natural and a trimodal sediment mixture, Water Resour. Res., 39(2), 1025, doi:10.1029/2001WR001088.

Blom, A., G. Parker, J. S. Ribberink, and H. J. de Vriend (2006), Vertical sorting and the morphodynamics of bed-form-dominated rivers: An equilibrium sorting model, J. Geophys. Res., 111, F01006, doi:10.1029/ 2004JF000175.

Di Silvio, G. (1992), Sediment exchange between stream and bottom: A four layer model, paper presented at International Grain Sorting Seminar, IAHR, Ascona, Switzerland.

Einstein, H. A. (1950), The bed-load function for sediment transportation in open channel flows, Tech. Rep. 1026, U.S. Dep. of Agric., Soil Conserv. Serv., Washington, D. C.

Gill, M. A. (1971), Height of sand dunes in open channel flows, J. Hydraul. Div., 97(HY12), 2067-2074.
Hassan, M. A., and M. Church (1994), Vertical mixing of coarse particles in gravel bed rivers: A kinematic model, Water Resour. Res., 30(4), 11731185 .

Hirano, M. (1970), On phenomena of river-bed lowering and armouring below reservoirs, paper presented at 14th Hydraulic Lecture Meeting, Civ. Eng. Assoc., Hydraul. Comm., Hatsumei Kaikan, 13-14 Feb.

Hirano, M. (1971), River bed degradation with armouring, Trans. Jpn. Soc. Civ. Eng., 3(2), 194-195.

Hirano, M. (1972), Studies on variation and equilibrium state of a river bed composed of nonuniform material, Trans. Jpn. Soc. Civ. Eng., 4, 128-129.

Leclair, S. F. and A. Blom (2005), A qualitative analysis of the distribution of bed-surface elevation and the characteristics of associated deposits for subaqueous dunes, in Fluvial Sedimentology VII, edited by M. D. Blum, S. B. Marriott, and S. F. Leclair, Spec. Publ. Int. Assoc. Sedimentol., 35, $121-134$.

Parker, G., C. Paola, and S. Leclair (2000), Probabilistic Exner sediment continuity equation for mixtures with no active layer, J. Hydraul. Eng., 126(11), 818-826.

Ribberink, J. S. (1987), Mathematical modelling of one-dimensional morphological changes in rivers with non-uniform sediment, Ph.D. thesis, Delft Univ., Delft, Netherlands.

Van der Mark, C. F., A. Blom, and S. J. M. H. Hulscher (2007), Variability in bedform characteristics using flume and river data, in River, Coastal and Estuarine Morphodynamics: RCEM 2007, edited by C. M. Dohmen-Janssen and S. J. M. H. Hulscher, pp. 923-930, Taylor and Francis, London.

Van Rijn, L. C. (1984), Sediment transport, part III: Bed forms and alluvial roughness, J. Hydraul. Eng., 110(12), 1733-1754.

Vanoni, V. A., and N. H. Brooks (1957), Laboratory studies of the roughness and suspended load of alluvial streams, Tech. Rep. E-68, Sediment. Lab., Calif. Inst. of Technol., Pasadena.

Wong Egoavil, M. (2006), Model for erosion, transport and deposition of tracer stones in gravel-bed streams, Ph.D. thesis, Univ. of Minn., Minneapolis.

A. Blom, Delft University of Technology, Civil Engineering and Geosciences, Environmental Fluid Mechanics Section, P.O. Box 5048, NL-2600 GA Delft, Netherlands. (astrid.blom@tudelft.nl)

J. S. Ribberink, University of Twente, Civil Engineering, P.O. Box 217, NL-7500 AE Enschede, Netherlands. (j.s.ribberink@utwente.nl)

G. Parker, Department of Civil and Environmental Engineering, University of Illinois at Urbana-Champaign, Urbana, IL 61801, USA. (parkerg@uiuc.edu) 